\title{
Blockchain Technology Investment and Sharing Strategy of Port Supply Chain Under Competitive Environment
}

\author{
Jiaguo LIU \\ School of Maritime Economics and Management, Dalian Maritime University, Dalian 116026, China \\ E-mail: liujiaguo@gmail.com \\ Huimin ZHANG \\ School of Maritime Economics and Management, Dalian Maritime University, Dalian 116026, China \\ E-mail: a15053839686@163.com \\ Huida ZHAO* \\ School of Maritime Economics and Management, Dalian Maritime University, Dalian 116026, China \\ E-mail: lskjd003@gmail.com

\begin{abstract}
Blockchain technology plays a very positive role in promoting the development of the port supply chain. Although there are some practical examples of blockchain in the port supply chain (eg. Trade Len or Cargo Smart), there are few application scenarios. Therefore, blockchain technology has yet to be widely used in the port industry. This may be related to the construction of blockchain. This paper analyzes the impact of blockchain technology on the port supply chain and the technology sharing on the shipping market. It is found that the investment of blockchain technology in a competitive environment has different characteristics. When the efficiency of technology investment and the proportion of market expansion reach a certain combination, there are two different equilibrium strategy choices: Only technology investment or technology sharing. Based on the above research results, this paper further investigates the results of the comprehensive influence of different factors such as competition intensity and market expansion proportion.
\end{abstract}

Keywords port supply chain; blockchain; technology investment; technology sharing; co-opetition

\section{Introduction}

\subsection{Background and Motivation}

Blockchain technology has gradually attracted widespread attention in the field of the industrial supply chain ${ }^{[1-3]}$. It can promote the transformation of the supply chain to higher transparency, lower cost, and faster business operation efficiency. It can increase the direct trust of supply chain enterprises, and ultimately improve the operation and management level of supply chain performance ${ }^{[4,5]}$. In the shipping industry, such as the support of blockchain technology in the digitization process, it can improve the customer relationship management of

Received July 14, 2020, accepted January 25, 2021

Supported by National Natural Science Foundation of China (71932002, 71774019)

* Corresponding author 
the shipping industry, enhance the business transparency of the enterprises, and play a positive role in promoting the development of shipping industry ${ }^{[6,7]}$. From the actual port and shipping business activities, we can find that IBM and Maersk jointly built a shipping blockchain solution (Trade Lens) to achieve digital operation ${ }^{1}$; Shanghai Port Group and COSCO Shipping Group realized transparent and paperless process with the help of blockchain technology ${ }^{2}$. Therefore, the introduction of blockchain technology has not only attracted the attention of shipping enterprises but also become an important field for researchers to study double-chain integration.

It can be found that the potential application of blockchain technology in the field of maritime shipping has gradually received widespread attention in the industry and the academic community. However, as cutting-edge technology with strong technical support, blockchain technology needs strong financial support before it can become an important weapon for enterprise development ${ }^{3}$. The problem lies in two aspects: Who will invest and how to invest. Who is going to invest needs to solve the problem of the main body of investment, whether it is an internal investment in the enterprise supply chain, or external investment ${ }^{[8]}$, investment of existing channels or investment of new channels ${ }^{[9]}$ ? Such problems are the first question that needs to be considered for new technologies or services. When the problem of the main body of investment is determined, the method of investment is required, namely, how to consider the investment coordination problem in the investment of new technologies or new services ${ }^{[10-12]}$. It shows that no matter what kind of investment, it is necessary to solve the basic problems before the system can be optimized for operation.

Our research aims to consider the impact of investment and sharing scenarios on the port supply chains and find a reasonable investment strategy. Combined with the existing research results, we comprehensively consider the impact of port investment blockchain technology in the competitive environment, namely, the discussion is divided into two stages. In the first stage, we are considering the impact on the market and economic effects of a single port investing in blockchain technology in a competitive environment. In the second stage, the technological competition environment, satisfactory investment technology, and the impact of technology sharing on the port market and economic effects are considered comprehensively. Besides, we also consider the impact of the change of competition intensity between ports on the choice of investment strategy to test the robustness of the conclusion. In the next section, we will discuss the contribution of the paper and the main findings.

\subsection{Research Questions and Major Findings}

Based on the above research, we analyze the port blockchain investment sharing problem from technology investment and technology sharing, respectively. According to the research problems, we have established a game model to analyze the following problems.

Q1: From the perspective of blockchain technology investment, how the dual ports are affected by the blockchain technology investment, that is to say, how the technology investment

\footnotetext{
${ }^{1}$ https://baijiahao.baidu.com/s?id $=1655581934295879875 \& w f r=$ spider $\&$ for $=$ pc.

${ }^{2}$ https://baijiahao.baidu.com/s?id=1662052467845855496\&wfr $=$ spider\&for $=$ pc.

${ }^{3}$ https://www2.deloitte.com/content/dam/Deloitte/cn/Documents/technology/deloitte-cn-consultingcrunch-time-4-zh-180531.
} 
affects the market and the economic effect of the port.

In terms of the market and economic effect of blockchain technology investment and dualport acquisition, the main change depends on the change of technology investment efficiency. Specifically, from the perspective of investment efficiency, we determine the impact of investment behavior on shipping market price, demand, and enterprise profit. From the perspective of shipping market prices, the port price of technology investment must rise. This is due to the increase in the price of the investment. Interestingly, for the port that does not invest, the shipping price is falling. The potential reason for this economic phenomenon is to maintain its unit income. At this time, the lower price will help maintain (or increase) its unit income. As for the demand change of the shipping market, the port investing in blockchain will increase its market demand. When there is a competition between the two ports and the market capacity is constant, the increase in demand on one side will inevitably lead to a decrease in demand on the other side. Given economic effects, the equilibrium strategy is obtained by analyzing the dominant strategies of the two ports. On the one hand, the efficiency requirements of investment blockchain technology should be met; on the other hand, when the investment efficiency needs to reach a more efficient state, the income of the two ports will reach equilibrium.

Q2: Under the premise of satisfying the port investment, the impact of blockchain technology sharing on the port market, and economic effect.

Another research question starts from the perspective of blockchain technology sharing, considering the changes and impact of market and economic effect after investment. From the perspective of the market effect, blockchain technology sharing reflects different results. Specifically, the price changes in the shipping market reflect a more complex situation, which is due to the significant impact of market expansion and investment efficiency. Considering the demand changes of the shipping market, under the premise of low and medium level market expansion, the demand for Port 2 after technology investment will be higher than that before sharing. However, when it is at a high expansion level, it shows multiple changes according to the change in investment efficiency. For Port 1, the change in demand is similar to Port 2. Specifically speaking, the technology sharing demand of Port 1 is better than that of investment in medium and low-level market expansion, while Port 1 shows different transition states in highlevel expansion. In terms of the demand change, the two ports are in a state of competition. From the perspective of economic effect, the two ports obtained their optimal economic returns, and the equilibrium strategy is obtained from the perspective of the equilibrium of the two enterprises. In addition, this paper further analyzes the change of competition coefficient to obtain the economic effects under the state of multi-parameter changes, which verifies the rationality and scientific of the results.

\subsection{Contribution Statements and Organization}

The contribution of this paper: Considering the operation practice of the existing maritime shipping enterprises, the paper uses game theory to extract the technology investment scenario of blockchain in the competitive environment, and the market and economic effect of the port in the technology sharing scenario. Furthermore, policy suggestions and management enlightenment are put forward. The research aims to find out how to realize the optimal investment and sharing scheme in the field of the port, to provide a reference for relevant practice. 
The structure of the paper is arranged as follows: In Section 2, we review the literature; In Section 3, the basic model and the model are introduced; In Section 4, we analyze the market and economic effect under the port competition state to find out the optimal investment scheme of the corresponding blockchain technology; In Section 5, based on satisfying the technological investment of blockchain, considering the market and economic effects of port technology sharing, a reasonable sharing scheme is proposed; In Section 6, we consider the stability of the results from the perspective of the change of competition parameters. Finally, the relevant conclusions and management implications are in Section 7. To show the results more clearly, we put the equilibrium strategy solution results and propositions' proof process in the Appendix.

\section{Literature Review}

Our research involves three aspects: 1) Related research on blockchain technology; 2) Related research on investment and operation of technology/service; 3) Related research on competition and cooperation of supply chain. This chapter mainly discusses the existing research in three aspects. To better explain the research contribution of this paper, we show its contribution to Table 1.

Table 1 Positioning of this study

\begin{tabular}{|c|c|c|c|c|c|c|}
\hline Literature & $\begin{array}{c}\text { Technology } \\
\text { Investment / } \\
\text { Sharing }\end{array}$ & $\begin{array}{c}\text { Business } \\
\text { Co-Competition }\end{array}$ & $\begin{array}{c}\text { Economic } \\
\text { Effect }\end{array}$ & $\begin{array}{c}\text { Market } \\
\text { Effect }\end{array}$ & $\begin{array}{l}\text { Block- } \\
\text { Chain }\end{array}$ & Game \\
\hline $\begin{array}{c}\text { Lu }(2017)^{[13]} \\
\text { Sande }(2018)^{[14]} \\
\text { Yang }(2019)^{[20]} \\
\text { Zhu }(2019)^{[16]}\end{array}$ & & & & & $\sqrt{ }$ & \\
\hline $\begin{array}{c}\text { Parast }(2020)^{[24]} ; \\
\text { Jena }(2019)^{[28]} ; \\
\end{array}$ & $\sqrt{ }$ & & & $\sqrt{ }$ & & \\
\hline $\begin{array}{l}\text { Lai }(2019)^{[23]} ; \\
\text { Yan }(2018)^{[22]}\end{array}$ & $\sqrt{ }$ & & $\sqrt{ }$ & $\sqrt{ }$ & & $\sqrt{ }$ \\
\hline $\begin{array}{l}\text { Xing, et al. }(2018)^{[35]} \text {; } \\
\text { Wang }(2019)^{[31]} ; \\
\text { Chen }(2020)^{[32]}\end{array}$ & & $\sqrt{ }$ & $\sqrt{ }$ & $\sqrt{ }$ & & $\sqrt{ }$ \\
\hline Choi $(2019)^{[15]}$ & $\sqrt{ }$ & & $\sqrt{ }$ & $\sqrt{ }$ & & $\sqrt{ }$ \\
\hline $\begin{array}{c}\text { Hafezalkotob }(2017)^{[27]} ; \\
\text { Li }(2019)^{[30]} ; \\
\text { Liu }(2019)^{[29]} ; \\
\text { Lin }(2020)^{[26]} ;\end{array}$ & $\sqrt{ }$ & $\sqrt{ }$ & $\sqrt{ }$ & $\sqrt{ }$ & & $\sqrt{ }$ \\
\hline Our paper & $\sqrt{ }$ & $\sqrt{ }$ & $\sqrt{ }$ & $\sqrt{ }$ & $\sqrt{ }$ & $\sqrt{ }$ \\
\hline
\end{tabular}


The research directly related to this paper is the application of blockchain technology in the supply chain. Specifically, the application of blockchain technology in supply chain management mainly focuses on product traceability and logistics traceability, process optimization, and paperless operation. From the research of product traceability and logistics traceability, we can find that the current research mainly focuses on case analysis, game theory, and so on. For example, $\mathrm{Lu}^{[13]}$ realized the product traceability system function under the complex supply chain environment with blockchain technology. Sander ${ }^{[14]}$ used blockchain technology in the tracking of meat products. Among them, the implementation of new technology seems to have a significant positive impact on consumers' purchasing decisions and is affected by consumers' quality perception. Choi ${ }^{[15]}$ used blockchain technology to analyze the traceability cost of luxury goods on different functional platforms and finds a reasonable operation scheme. $\mathrm{Zhu}^{[16]}$ pointed out that the use of blockchain technology can rationalize the decision-making of supply chain entities in product management, and provide relevant management insights. The research on process optimization and paperless operation mainly focuses on a case study or qualitative research. For example, Civelek ${ }^{[17]}$ pointed out that the use of blockchain technology can help reduce the emergence of paper-based circulation documents and provide document integrity without requiring a third party to act as a trusted third party. Chang ${ }^{[18]}$ studied the feasibility of technology and supply chain process reengineering and designed a technology framework based on technology to enhance the flexibility and transparency of business activities of enterprises. The preliminary application of Choi ${ }^{[19]}$ used blockchain technology for information disclosure to increase the scientific decision-making of consumers and enterprises. As for the blockchain technology in the maritime shipping field, there are also many research results. For example, Yang ${ }^{[20]}$ explained that shipping enterprises have a positive impact on the use of blockchain technology from the aspects of shipping system standardization and platform development dimension, and puts forward potential design scheme for future construction of shipping digitization. Lambourdiere ${ }^{[21]}$ illustrated that blockchain technology is invisible in the field of shipping from the perspective of dynamic capabilities. It can increase the performance level of shipping enterprises' supply chain by using the capabilities or resources provided by the maritime supply chain. Our research mainly considers the decision-making problem of blockchain technology in shipping enterprises. Different from the existing research, this research uses the game model to consider how to invest and share technology from the perspective of decision-making, which makes the decision-making of shipping enterprises scientific and feasible. Besides, the research of blockchain technology mainly considers the problem of the industrial supply chain, and the results of the research on the port supply chain are relatively lacking. Therefore, this research is different from the current research results in the research industry. In this way, the development significance of blockchain technology is more important to shipping enterprises.

The existing research analyzes from the perspective of technology investment or service investment operation, aiming to investigate the impact of enterprise investment and operation behavior on supply chain performance. For example, Yan $^{[22]}$ studied the question of whether the green investment in retailers' products should be invested and whether it is appropriate to invest. Lai ${ }^{[23]}$ analyzes the motivation of the port's forecasted information sharing and 
the impact of the carrier's risk behavior on the sustainable investment decision of the port supply chain. Parast ${ }^{[24]}$ found that R\&D and innovation investment can be used as one of the means to improve the flexibility of enterprises to deal with supply chain interruption, which helps to reduce the impact of process interruption and environmental disruption on supply chain performance. Dong ${ }^{[25]}$ studied the strategic investment of green product development in the supply chain environment. Lin ${ }^{[26]}$ considers the ecological innovation decisions of different supply chain structures and considers whether two suppliers decide their ecological innovation level unilaterally or coordinate an innovation alliance. The results show that the knowledge spillover and technology gap have a significant impact on suppliers' level of ecological innovation, economic benefits, and total social welfare. The research aims to illustrate the impact of new technology (or service) on the overall supply chain investment decisions. The purpose of this paper is to think about the impact of blockchain technology investment on the market and the economic effect of the whole supply chain. The specific manifestation is the impact on market prices and corporate earnings. From this viewpoint, although there are no research differences, this paper considers the impact of investment and technology sharing from the perspective of two stages. Therefore, it can be shown that the research in this paper is different from other research results.

The existing research is reflected in the competition and cooperation of different entities in the supply chain. Specifically, different entities around the unified goal setting, and determine their own optimal or specific optimal operation strategy and scheme. Supply chain coordination can be realized through business competition and cooperation. For example, Hafezalkotob ${ }^{[27]}$ established a model of price-saving competition and cooperation between two green supply chains under government financial intervention and pointed out that the cooperation between supply chains can promote the government's sustainable development policies. Jena ${ }^{[28]}$ pointed out that the two tourism enterprises compete in price and service through the common local operator, which generates more profits than without competition. Liu ${ }^{[29]}$ examined the possible alliance between the two shipping companies, which weakened the business competition, port service price, and the monopoly advantage of the port. $\mathrm{Li}^{[30]}$ pointed out that in the scenario of dual-channel exhibition hall competition, the competition will increase the profits of existing online retailers; information asymmetry is unfavorable to all members of the supply chain, which means that offline exhibition halls can share information with online retailers. Wang ${ }^{[31]}$ pointed out that the manufacturer's dual-channel strategy would reduce the profits of traditional retailers under the platform environment. Compared with the manufacturer's pricing model, the platform pricing model always cannibalizes some profits that the manufacturers obtain through the dual-channel strategy. Chen ${ }^{[32]}$ analyzed the e-commerce platform based on the game model and pointed out that the irregular development of the telecom payment market will also lead to the third-party trading enterprises occupying the "three major" dominant position in the "multipower" market structure. The above research mainly considers supply chain competition and cooperation.

According to our research question, we also focus on the port cooperation of the supply chain. Specifically, from the perspective of supply chain cooperation between the port and port user, Seo, et al. ${ }^{[33]}$ pointed out the container transportation has a positive impact on 
the collaborative advantage of a port which helps improve port performance. Song, et al. ${ }^{[34]}$ considered a line company to dock at one of the two heterogeneous ports, and the choice of port investment is often battered than business cooperation. Besides, when a shipping company comes to an investment agreement with one port, the other port will also profit. Xing, et al. ${ }^{[35]}$ analyzed the impact on social welfare, customer surplus, and environmental benefits of two pricing strategies which are price discrimination price and uniform price of ports under the neighboring ports share the same overlapping hinterland with the third port. $\mathrm{Wu}$ and Yang ${ }^{[36]}$ considered motivation, mode, and result of port cooperation and integration from the perspective of port government, and provided the professional path for port cooperation, which is an integrated and coordinated project to achieve the optimal shipping mode system. Wang, et al. ${ }^{[37]}$ constructed a non-cooperative game model with a two-terminals-one-port system and gave the optimal equilibrium result of investment expansion strategy and investment constant strategy to solve the problem of container port congestion. Compared with the existing research results, the main difference of this paper is that the investment and sharing of blockchain technology are considered from the perspective of two ports' competition and cooperation, and comprehensively consider the competition between ports to achieve the optimal operation strategy.

\section{Model}

\subsection{Assumption and Notation}

In this paper, we use the Cournot model to analyze the competition between channels ${ }^{[38,39]}$, so that we can better understand the ports' choice to invest in blockchain technology and its technology sharing behavior. Based on the research questions and purpose, we make the following assumptions:

1) Determination of analysis scene. According to the general law of new technology introduction, we have determined three discussion scenarios, namely, the ports of both channels do not introduce blockchain technology (NA strategy); Port 2 introduces the investment strategy of blockchain technology ( $I$ Strategy); Based on the introduction of blockchain technology in Port 2, a blockchain technology sharing behavior is generated ( $S$ strategy). This behavior is embodied in Port 2 sharing the blockchain technology $(e)$ with Port 1 . However, Port 1 is required to apportion part of its overall revenue $(\theta)$ as compensation for the use of technology. The results are shown in Figure 1.

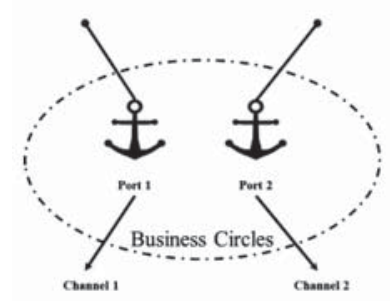

(a) NA strategy

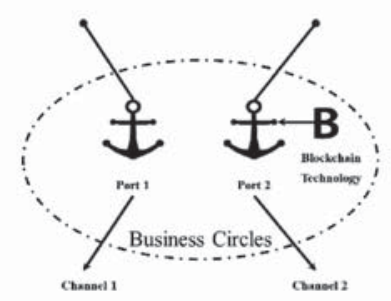

(b) I strategy

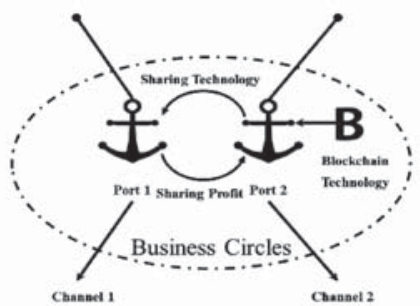

(c) S strategy

Figure 1 Analysis scenario 
2) The Cournot model is used as the basic model to determine the demand expression of the chain (or channel) where the two ports are located. Therefore, the requirements of the two ports in the basic scenario are expressed as $p_{1}^{\mathrm{NA}}=a-q_{1}^{\mathrm{NA}}-b q_{2}^{\mathrm{NA}}$ and $p_{2}^{\mathrm{NA}}=a-q_{2}^{\mathrm{NA}}-b q_{1}^{\mathrm{NA}}$. The parameter $b$ represents the intensity of competition between the two ports. In the basic discussion, determine the parameter $b=1$, that is to say, considering the situation that the two ports completely replace each other;

3) Determination of market scope. As a new technical means to effectively coordinate supply chain activities, blockchain technology can reduce the operation cost of the system, improve the system capacity and enhance the purchase experience of consumers (Martinez, 2019 ${ }^{[40]}$ ). Therefore, considering the investment in blockchain technology of Port 2, the overall market capacity will be expanded from $a$ to $(1+m) a$, and the parameter $m$ is the proportion of market expansion;

4) Determination of investment cost. Port 2 determines the input cost of the port is $\frac{K}{2} e^{2}$. This $K$ is the parameter to measure the investment efficiency of blockchain technology. Under other conditions unchanged, the smaller the value of $K$, the higher the investment efficiency; otherwise, the lower the investment efficiency. In addition, $e$ is the actual investment level of blockchain technology;

5) Determination of profit function. According to the research setting of classical economics, for the two ports, the profit expression is determined based on the principle of revenue maximization.

To better show the research problems of this paper, we summarize the parameters in Table 2. The superscripts "NA", "I" and "S" represent non-investment operation strategies, Port 2 investment blockchain technology operation strategies, and Port 2 investment and sharing blockchain technology operation strategies, respectively. For the convenience of expression, we determine the parameter table, as shown in Table 2.

Table 2 Variables and parameters in the model

\begin{tabular}{|c|c|c|c|}
\hline \multicolumn{4}{|c|}{ Decision variables } \\
\hline Symbol & Description & Symbol & Description \\
\hline$p_{1}$ & The market price of Port 1 & $p_{2}$ & The market price of Port 2 \\
\hline$q_{1}$ & The market demand of Port 1 & $q_{2}$ & The market demand of Port 2 \\
\hline$\pi_{1}$ & Economic profit of Port 1 & $\pi_{2}$ & Economic profit of Port 2 \\
\hline$e$ & \multicolumn{3}{|c|}{ Investment level of blockchain technology } \\
\hline \multicolumn{4}{|c|}{ Parameter } \\
\hline$\theta$ & \multicolumn{3}{|c|}{ The proportion of blockchain technology profit sharing } \\
\hline$K$ & \multicolumn{3}{|c|}{ Investment efficiency of blockchain technology } \\
\hline$b$ & \multicolumn{3}{|c|}{ Competition intensity of shipping market } \\
\hline$m$ & \multicolumn{3}{|c|}{ The increasing proportion of market capacity after adopting blockchain technology } \\
\hline \multicolumn{4}{|c|}{ Constant } \\
\hline$a$ & \multicolumn{3}{|c|}{ The total capacity of the shipping market } \\
\hline
\end{tabular}




\subsection{Demand Function and Profit Function}

According to the assumptions, we determine the demand and profit expressions in different scenarios. The results are shown in Table 3. It is worth noting that in the scenario of technology sharing, based on the collection of the overall profit of Port 1, the total amount of profit transferred to Port 2 is $\theta\left(p_{1}^{S} q_{1}^{S}+e^{S} q_{1}^{S}\right)$.

Table 3 Profit function

\begin{tabular}{ccc}
\hline Scenes & Cournot model & Profit function \\
\hline \multirow{2}{*}{$\mathrm{NA}$} & $p_{1}^{\mathrm{NA}}=a-q_{1}^{\mathrm{NA}}-b q_{2}^{\mathrm{NA}}$ & $\pi_{1}^{\mathrm{NA}}=p_{1}^{\mathrm{NA}} q_{1}^{\mathrm{NA}}$ \\
\cline { 2 - 3 } & $p_{2}^{\mathrm{NA}}=a-q_{2}^{\mathrm{NA}}-b q_{1}^{\mathrm{NA}}$ & $\pi_{2}^{\mathrm{NA}}=p_{2}^{\mathrm{NA}} q_{2}^{\mathrm{NA}}$ \\
\hline \multirow{2}{*}{$I$} & $p_{1}^{I}=a-q_{1}^{I}-b q_{2}^{I}$ & $\pi_{1}^{I}=p_{1}^{I} q_{1}^{I}$ \\
\cline { 2 - 3 } & $p_{2}^{I}=(1+m) a-q_{2}^{I}-b q_{1}^{I}+e^{I}$ & $\pi_{2}^{I}=p_{2}^{I} q_{2}^{I}-\frac{K}{2}\left(e^{I}\right)^{2}$ \\
\hline \multirow{2}{*}{$S$} & $p_{1}^{S}=a-q_{1}^{S}-b q_{2}^{S}+e^{S}$ & $\pi_{1}^{S}=\left(p_{1}^{S} q_{1}^{S}+e^{S} q_{1}^{S}\right)(1-\theta)$ \\
\cline { 2 - 3 } & $p_{2}^{S}=(1+m) a-q_{2}^{S}-b q_{1}^{S}+e^{S}$ & $\pi_{2}^{S}=p_{2}^{S} q_{2}^{S}-\frac{K}{2}\left(e^{S}\right)^{2}+\theta\left(p_{1}^{S} q_{1}^{S}+e^{S} q_{1}^{S}\right)$ \\
\hline
\end{tabular}

\subsection{Decision Sequence}

The decision-making sequence of events is described as following according to different scenarios:

1) In the NA scenario, Port 1 and Port 2 do not use technology input and determine the shipping market price $p$ and shipping market demand of the two ports $q$ at the same time. Finally, they determine the economic profit of each port;

2) In the scenario $I$, Port 2 first determines the level of technology input $e^{I}$; Then, Port 1 and Port 2 determine the shipping market price $p$ and demand of the two ports $q$ at the same time; Finally, they determine the economic profit of each port;

3) In the $S$ scenario, Port 2 first determines the level of technical input $e^{S}$; Then, Port 1 and Port 2 determine the shipping market price $p$ and demand of the two ports $q$ at the same time; Finally, they determine the economic profit of each port;

According to the inverse solution rule, we can get the results as shown in Appendix A. In Section IV, we explain the strategy of port blockchain technology investment and the choice of port blockchain technology sharing strategy in two discussion stages.

\section{Analysis}

Based on the equilibrium results, we investigate the market and economic effect in the process of competition of two ports from the perspective of investment and sharing analysis, and seek the optimal investment and sharing operation strategy.

\subsection{Stage I: Investment Effect}

In the first stage of the analysis, we consider the investment effect related issues. Specifically, this paper discusses the strategy of non-investment and Port 2 investment blockchain technology in the design scenario, which aims to find out the change in investment behavior on the shipping market and economic effect of different ports and obtain the optimal investment and operation 
strategy.

\subsubsection{Market Effect of Shipping Enterprises}

This part analyzes the impact of Port 2 blockchain technology investment behavior on price and demand from the perspective of shipping market price and shipping market demand. Specifically, we can get the comparison results of the shipping market effect between Proposition 1 and Proposition 2.

Proposition 1 (Analysis of Shipping Market Effect) Considering the impact of blockchain technology on shipping market price before and after investment.

(a) For Port 1, when the investment efficiency satisfies $K>\frac{8}{\left(4-b^{2}\right)^{2}}$, the market price after the investment is lower than that pre-investment;

(b) For Port 2, when the investment efficiency satisfies $K>\frac{8}{\left(4-b^{2}\right)^{2}}$, the market price after the investment is higher than that pre-investment.

By controlling the investment efficiency of blockchain technology, the port can adjust the effect of the shipping price. On the whole, the investment efficiency of blockchain technology

needs to satisfy $K>\frac{8}{\left(4-b^{2}\right)^{2}}$ from the numerical point of view, and the corresponding concept represents the minimum investment efficiency. From the mathematical point of view, it is easy to know that when other conditions remain unchanged, the higher the investment efficiency, the less investment, and the better benefit, it is the optimal situation, and the numerical change shows a reverse change state. From the perspective of economic meaning, when the minimum efficiency requirement of investment is met, Port 1 and Port 2 can exhibit different price changes. From Proposition 1 (a), it can be found that when the investment strategy is adopted, Port 1 is affected by Port 2's investment behavior, and its terminal price will be lower than the market price without investment. But from the discussion of Proposition 1 (b), it can be found that the market price of Port 2 after investment will be higher than that pre-investment. The reason is obvious, that is to say, Port 2 will increase its investment in operating costs after making blockchain technology investment. Therefore, it will inevitably lead to the market price of Port 2 higher than the market price pre-investment, which is also a disguised compensation for the loss caused by investment. Combined with the changes in shipping market demand, Port 1 will reduce its price to maintain its revenue while maintaining a certain capacity to obtain its market share. The following examines the impact of market investment behavior from the perspective of demand change.

Proposition 2 (Analysis of Shipping Market Demand) Considering the impact of blockchain technology on the shipping market demand before and after the investment.

(a) For Port 1, when the investment efficiency meets $K>\frac{8}{\left(4-b^{2}\right)^{2}}$, the market demand after the investment is lower than that pre-investment;

(b) For Port 2, when the investment efficiency meets $K>\frac{8}{\left(4-b^{2}\right)^{2}}$, the market demand after the investment is higher than that pre-investment.

Proposition 2 reflects the impact of investment behavior on the market demand of the two ports. From Proposition 2 (a), it can be found that the market demand of Port 1 is lower than that of pre-investment because of the influence of Port 2's investment behavior. Proposition 2 (b) reflects that based on satisfying the conditions of investment efficiency, the market demand 
after the investment is higher than that of pre-investment. It is easy to know that the impact of technology or service investment on market demand (Yang, 2020 ${ }^{[41]}$ ). Under the premise of fixed market capacity, the enterprise adopting new technology will increase the market share of the enterprise with the guidance of the new way, which will help to enhance the market demand of the enterprise. With other conditions unchanged, competitiveness will cause a decrease in market capacity of Port 1 and the increase of market capacity of Port 2. Combined with the performance of market price, we can find that the root lies in the influence of competition, that is to say, the competition effect under the condition of new technology. This effect allows weak ports to reduce their price to maintain their original market capacity. The reason lies in the competition brought by new technology deprives the original enterprises (Port 1) of their market capacity. Combining the market effect of the two ports, we can get the economic effect of shipping market enterprises.

\subsubsection{Comparison of Profits in Shipping Market Enterprises}

Through the analysis of market benefits, we can get the influence of price and demand change in different ports. However, the enterprise hopes to obtain profits. That is to say, analyzing the impact of investment on itself and considering its investment decision-making strategy from the perspective of rational people. However, for counterpart (Port 1), it often considers the impact of investment on itself. That is to say, the impact of passive investment behavior on its income. In summary, how investment behavior affects the investment strategy choice of competitive ports. Therefore, we can get the economic effect of shipping market enterprises in this way. In short, we should know how the enterprise's income is affected by the perspective of income. The results are shown in Proposition 3.

Proposition 3 (Analysis of Economic Effect of Shipping Market) Considering the economic impact of blockchain technology on shipping enterprises before and after investment.

(a) For Port 1, when the investment efficiency meets $\frac{8}{\left(4-b^{2}\right)^{2}}<K<\frac{4(4+b)}{(2+b)^{2}(2-b)(4-b(2+m))}$, the investment in blockchain technology is better than the income obtained by not investing in blockchain technology; when the investment efficiency meets $K>\frac{4(4+b)}{(2+b)^{2}(2-b)(4-b(2+m))}$, the return of not investing in blockchain technology is superior to investing in blockchain technology;

(b) For Port 2, when the investment efficiency meets $K>\frac{8}{\left(4-b^{2}\right)^{2}}$, the economic benefit of investment in blockchain technology is higher than that without investment.

From Proposition 3, we can find the impact of investment behavior on ourselves and rivals. From Proposition 3 (a), we can find that under the influence of Port 1's passive investment activities, there are two kinds of income, namely, the enterprise's income affected by investment efficiency. When the efficiency of technology investment is high (satisfying $\left.\frac{8}{\left(4-b^{2}\right)^{2}}<K<\frac{4(4+b)}{(2+b)^{2}(2-b)(4-b(2+m))}\right)$, the return is higher than that of Port 2, which does not invest in blockchain technology; when the investment efficiency becomes low and meets a certain condition $\left(K>\frac{4(4+b)}{(2+b)^{2}(2-b)(4-b(2+m))}\right)$, it is optimal to not invest. There are two potential reasons for this phenomenon. On the one hand, it is the spillover effect of technology investment. Its concrete lies in the influence of investment behavior on both sides. If one enterprise takes the blockchain technology investment, it will lead the other enterprises to obtain an invisible influence. The interaction between the demand and price of the two ports can be 
found after driving force manifests. Whether Port 1 wants to accept the influence of technology or not, its spillover effect will affect the enterprise's revenue. On the other hand, enterprise competition brings potential "competitive profits". Therefore, to obtain higher profits, enterprises will also consider using other means to obtain profits. As far as Port 1 is concerned, it can only consider how to adjust the price changes from the perspective of price to obtain its maximum benefit. Therefore, when Port 1 obtains its maximum profit, the enterprise adopts price instruments to cope with the impact of Port 2 investment. In Proposition 3 (b), it can be found that the benefits of investing in blockchain technology are better than those of not investing in blockchain. The reason for this phenomenon is obvious, that is to say, the price and quantity will increase after investment, and the comprehensive income can be obtained. Therefore, when the blockchain technology investment is adopted, it can bring potential benefits. When we consider the investment problem from the perspective of equilibrium, we can find a comprehensive and optimal balanced investment scheme and put forward the corresponding management enlightenment. The regularity feature can be found in the result of Proposition 4.

Proposition 4 (Equilibrium Selection Based on Economic Effect) Consider the optimal investment strategy of blockchain technology from the perspective of economic effect.

From the view of economic effects in the two ports, the optimal investment scheme can be obtained. That is to say, when the investment efficiency satisfies $\frac{8}{\left(4-b^{2}\right)^{2}}<K<\frac{4(4+b)}{(2+b)^{2}(2-b)(4-b(2+m))}$, the two ports' income will be positively affected, which is the optimal choice of investment strategy (As shown in Figure 2).

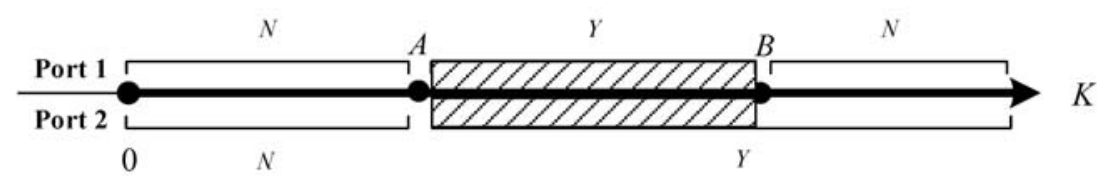

Figure 2 The first stage of the port investment equilibrium strategy

Proposition 4 reflects the investment strategy selection scheme of Ports 1 and 2 equilibrium strategies. In Figure 2, we can find that point A to point B is balanced investment strategies. At this time, the profit of Port 1 and Port 2 can be satisfied. The management enlightenment can be considered from two aspects: On the one hand, maintaining reasonable technology investment efficiency. Maintaining reasonable investment efficiency is helpful to enhance the dual port's balance of income. When investment efficiency gradually decreases, with the other conditions remain unchanged, the benefits brought by the technology will gradually decrease, which may lead to insufficient income, and the phenomenon of "small horse pulling a big cart" will occur. On the other hand, maintaining a reasonable investment efficiency of blockchain technology. As far as enterprises are concerned, they should raise their stations to the height of digital strategy, and use data analysis and machine learning technology to optimize the investment and operation efficiency of ports, to meet the existing or future needs of ports (Shipping Industry, 2017 ). Therefore, when one enterprise invests in blockchain technology, the other one will be affected. Setting a reasonable investment efficiency ratio is conducive to the common development of enterprises.

\footnotetext{
${ }^{4}$ https://www.sohu.com/a/167317937_173888.
} 
Based on the analysis of the first stage, we examine the impact of investment on competitive ports' operation from the perspective of blockchain technology investment, aiming to find a reasonable technology investment strategy from the perspective of investment efficiency to meet the requirements of balanced income and strategy. From the analysis of the second stage, considering the two scenarios of Port 2 including blockchain technology investment and sharing, we find a reasonable investment and sharing scheme, which makes the two ports reach a balanced operation strategy.

\subsection{Second Stage Analysis: Sharing Effect}

In the first stage of the analysis, considering the relevant issues of investment effects, and find out the balanced strategy of investment behavior for shipping blockchain technology in different ports. In the second stage, considering the related problems of investment and technology sharing behavior, and examining the influence of technology sharing on competitive ports, we can find out the reasonable benefit distribution scheme and achieve the balance of the benefit between ports.

\subsubsection{Market Effect of Shipping Enterprises}

This section describes the impact of blockchain technology investment and sharing behavior among competitive port enterprises on shipping market price and market demand from two aspects. It is worth noting that the investment of blockchain technology will affect market capacity. Therefore, considering the increased market capacity ratios $m=1 / 4, m=2 / 4$, and $m=3 / 4$ comprehensively, we get the conclusion. From the above, the discussion results of Proposition 5 and Proposition 6 can be obtained.

Proposition 5 (Analysis of Shipping Market Effect) Consider the impact of blockchain technology on shipping market prices before and after sharing.

(a) For Port 1, the shipping market price has the following changes:

a. When $m=1 / 4, \theta \in\left(0, \frac{105-9 \sqrt{97}}{44}\right)$ and $K>\frac{8}{9}, p_{1}^{I}<p_{1}^{S} ; \theta \in\left(\frac{105-9 \sqrt{97}}{44}, 1\right)$ and $K>$ $\frac{2(9-2 \theta) \theta}{(3-\theta)^{2}}, p_{1}^{I}<p_{1}^{S}$

b. When $m=2 / 4, \theta \in\left(0, \frac{105-9 \sqrt{97}}{44}\right)$ and $K>\frac{8}{9}, p_{1}^{I}<p_{1}^{S} ; \theta \in\left(\frac{105-9 \sqrt{97}}{44}, 1\right)$ and $K>$ $\frac{2(9-2 \theta) \theta}{(3-\theta)^{2}}, p_{1}^{I}<p_{1}^{S}$

c. When $m=3 / 4, \theta \in\left(0, \frac{105-9 \sqrt{97}}{44}\right)$ and $K>\frac{8}{9}, p_{1}^{I}<p_{1}^{S} ; \theta \in\left(\frac{105-9 \sqrt{97}}{44}, 1\right)$ and $K>\frac{1}{3}\left(-7+\frac{45}{3-\theta}-\frac{20}{\theta}+\frac{\sqrt{3600-\theta(5280-\theta(3256-\theta(824-289 \theta)))}}{(3-\theta) \theta}, p_{1}^{I}<p_{1}^{S} ; \theta \in\left(\frac{105-9 \sqrt{97}}{44}, 1\right)\right.$ and $\frac{2(9-2 \theta) \theta}{(3-\theta)^{2}}<K<\frac{1}{3}\left(-7+\frac{45}{3-\theta}-\frac{20}{\theta}+\frac{\sqrt{3600-\theta(5280-\theta(3256-\theta(824-289 \theta)))}}{(3-\theta) \theta}\right), p_{1}^{I}>p_{1}^{S}$.

(b) For Port 2, the shipping market price has the following changes:

a. When $m=1 / 4 \theta \in\left(0, \frac{105-9 \sqrt{97}}{44}\right)$ and $\frac{8}{9}<K<\frac{72-36 \theta+13 \theta^{2}+\sqrt{5184-5184 \theta-4608 \theta^{2}+2952 \theta^{3}-263 \theta^{4}}}{9(3-\theta) \theta}$, $p_{2}^{I}>p_{2}^{S} ; \theta \in\left(0, \frac{105-9 \sqrt{97}}{44}\right)$ and $K>\frac{72-36 \theta+13 \theta^{2}+\sqrt{5184-5184 \theta-4608 \theta^{2}+2952 \theta^{3}-263 \theta^{4}}}{9(3-\theta) \theta}, p_{2}^{I}<p_{2}^{S}$; $\theta \in\left(\frac{105-9 \sqrt{97}}{44}, \theta_{1}\right)$ and $\frac{72-36 \theta+13 \theta^{2}-\sqrt{5184-5184 \theta-4608 \theta^{2}+2952 \theta^{3}-263 \theta^{4}}}{9(3-\theta) \theta}<K<\frac{72-36 \theta+13 \theta^{2}+\sqrt{5184-5184 \theta-4608 \theta^{2}+2952 \theta^{3}-263 \theta^{4}}}{9(3-\theta) \theta}$, $p_{2}^{I}>p_{2}^{S} ; \theta \in\left(\frac{105-9 \sqrt{97}}{44}, \theta_{1}\right)$ and $\frac{18 \theta-4 \theta^{2}}{9-6 \theta+\theta^{2}}<K<\frac{72-36 \theta+13 \theta^{2}-\sqrt{5184-5184 \theta-4608 \theta^{2}+2952 \theta^{3}-263 \theta^{4}}}{9(3-\theta) \theta}$, $p_{2}^{I}<p_{2}^{S} ; \theta \in\left(\frac{105-9 \sqrt{97}}{44}, \theta_{1}\right)$ and $K>\frac{72-36 \theta+13 \theta^{2}+\sqrt{5184-5184 \theta-4608 \theta^{2}+2952 \theta^{3}-263 \theta^{4}}}{9(3-\theta) \theta}, p_{2}^{I}<p_{2}^{S} ;$ 


$$
\begin{aligned}
& \theta \in\left(\theta_{1}, 1\right) \text { and } K>\frac{18 \theta-4 \theta^{2}}{9-6 \theta+\theta^{2}}, p_{2}^{I}<p_{2}^{S} . \\
& \quad \text { b. When } m=2 / 4, \theta \in\left(0, \frac{105-9 \sqrt{97}}{44}\right) \text { and } \frac{8}{9}<K<\frac{2\left(24-14 \theta+5 \theta^{2}\right)+2 \sqrt{576-672 \theta+4 \theta^{2}+76 \theta^{3}+\theta^{4}}}{3(3-\theta) \theta} \\
& p_{2}^{I}>p_{2}^{S} ; \theta \in\left(0, \frac{105-9 \sqrt{97}}{44}\right) \text { and } K>\frac{2\left(24-14 \theta+5 \theta^{2}\right)+2 \sqrt{576-672 \theta+4 \theta^{2}+76 \theta^{3}+\theta^{4}}}{3(3-\theta) \theta}, p_{2}^{I}<p_{2}^{S} ; \theta \in \\
& \left(\frac{105-9 \sqrt{97}}{44}, \theta_{2}\right) \text { and } \frac{2\left(24-14 \theta+5 \theta^{2}\right)-2 \sqrt{576-672 \theta+4 \theta^{2}+76 \theta^{3}+\theta^{4}}<K<\frac{2\left(24-14 \theta+5 \theta^{2}\right)+2 \sqrt{576-672 \theta+4 \theta^{2}+76 \theta^{3}+\theta^{4}}}{3(3-\theta) \theta}}{3(3-\theta) \theta} \\
& p_{2}^{I}>p_{2}^{S} ; \theta \in\left(\frac{105-9 \sqrt{97}}{44}, \theta_{2}\right) \text { and } \frac{18 \theta-4 \theta^{2}}{9-6 \theta+\theta^{2}}<K<\frac{2\left(24-14 \theta+5 \theta^{2}\right)-2 \sqrt{576-672 \theta+4 \theta^{2}+76 \theta^{3}+\theta^{4}}}{3(3-\theta) \theta}, p_{2}^{I}< \\
& p_{2}^{S} ; \theta \in\left(\frac{105-9 \sqrt{97}}{44}, \theta_{2}\right) \text { and } K>\frac{2\left(24-14 \theta+5 \theta^{2}\right)+2 \sqrt{576-672 \theta+4 \theta^{2}+76 \theta^{3}+\theta^{4}}}{3(3-\theta) \theta} ; \theta\left(\theta_{2}, 1\right) \text { and } K> \\
& \frac{18 \theta-4 \theta^{2}}{9-6 \theta+\theta^{2}}, p_{2}^{I}<p_{2}^{S} . \\
& \quad \mathrm{c} . \text { When } m=3 / 4, \theta \in\left(0, \frac{105-9 \sqrt{97}}{44}\right) \text { and } \frac{8}{9}<K<\frac{120-76 \theta+27 \theta^{2}+\sqrt{14400-18240 \theta+7936 \theta^{2}-1944 \theta^{3}+489 \theta^{4}}}{3(3-\theta) \theta} \\
& p_{2}^{I}>p_{2}^{S} ; \theta \in\left(0, \frac{105-9 \sqrt{97}}{44}\right) \text { and } K>\frac{120-76 \theta+27 \theta^{2}+\sqrt{14400-18240 \theta+7936 \theta^{2}-1944 \theta^{3}+489 \theta^{4}}}{3(3-\theta) \theta}, p_{2}^{I}<p_{2}^{S} ; \\
& \theta \in\left(\frac{105-9 \sqrt{97}}{44}, 1\right) \text { and } \frac{18 \theta-4 \theta^{2}}{9-6 \theta+\theta^{2}}<K<\frac{120-76 \theta+27 \theta^{2}+\sqrt{14400-18240 \theta+7936 \theta^{2}-1944 \theta^{3}+489 \theta^{4}}}{3(3-\theta) \theta}, p_{1}^{I}<p_{1}^{S} ; \\
& \theta \in\left(\frac{105-9 \sqrt{97}}{44}, 1\right) \text { and } K>\frac{120-76 \theta+27 \theta^{2}+\sqrt{14400-18240 \theta+7936 \theta^{2}-1944 \theta^{3}+489 \theta^{4}}}{3(3-\theta) \theta}, p_{1}^{I}<p_{1}^{S} .
\end{aligned}
$$

Proposition 5 shows the impact of blockchain technology sharing behavior on terminal price. All in all, it can be found that the terminal price of the shipping market changes with the expansion of the market, and the two ports show a more complex trend in price changes. Specifically, from Proposition 5 (a), we can find that the price of Port 1 exhibits different results under the influence of different market expansion ratios. When the market expansion level is low and it meets the corresponding investment restrictions of blockchain technology, the price of sharing scenario is higher than the terminal price of the investment. When the share ratio reaches the highest and the investment efficiency is at a certain level $\left(\frac{2(9-2 \theta) \theta}{(3-\theta)^{2}}<K<\frac{1}{3}\left(-7+\frac{45}{3-\theta}-\frac{20}{\theta}+\frac{\sqrt{3600-\theta(5280-\theta(3256-\theta(824-289 \theta)))}}{(3-\theta) \theta}\right)\right)$, the price of the investment scenario is higher than the sharing scenario. The price is affected by the profit-sharing ratio. When the market expansion ratio is at a low or medium level, Port 1 will pay a part of the revenue as a "shareholding" fee to support Port 2's blockchain technology construction while acquiring shared technology. At this time, in addition to the original price cost, the acquired price composition also includes the cost apportioned in the external expenses. Whether the profit-sharing ratio is high or low, it will increase its expenditure costs. The investment behavior obtained at this time is the active technology input behavior of Port 1, which is transferred to its price. Therefore, the economic phenomenon of increasing prices is shown in the sharing scenario. When the market expansion ratio reaches a high level, there is a problem of efficiency change At this time, when the profit-sharing ratio reaches a high level, Port 1 has different strategic choices because of the heterogeneity of investment efficiency, and the terminal price changes. Specifically, when the investment efficiency reaches a certain threshold range $\left(\frac{2(9-2 \theta) \theta}{(3-\theta)^{2}}<K<\frac{1}{3}\left(-7+\frac{45}{3-\theta}-\frac{20}{\theta}+\frac{\sqrt{3600-\theta(5280-\theta(3256-\theta(824-289 \theta)))}}{(3-\theta) \theta}\right)\right.$, the sharing price of Port 1 will be lower than the terminal price which only affected by investment behavior. However, the price of technology sharing scenario is higher than Port 2 alone. The potential reason for this phenomenon lies in the influence of technology investment efficiency and market expansion. At this time, when the proportion of revenue analysis is at a high level, Port 2 will choose its subsequent behavior according to investment efficiency.

From Proposition 5 (b), we can get the change of terminal market price of Port 2. Through the analysis results, it can be found that the technology investment scenario and sharing scenario 
show more complicated changing characteristics with the influence of different variables. When the market expansion ratio reaches a low level, the price change of Port 2 shows the same trend. Specifically, low share ratio and high investment efficiency will lead to the price of Port 2 higher than that in sharing; low sharing ratio and low investment efficiency will lead to the price of sharing scenarios higher than the price of independent construction. From the view of the high share ratio, the relatively high investment efficiency will make the price of Port 2 higher than the price of sharing; when the investment efficiency is lower, the scenario of choosing technology sharing is higher than the scenario of choosing an independent investment. When the market expansion ratio reaches a high level, high technology investment efficiency and low sharing ratio can make the price of choosing independent investment than the scenario of choosing to share; when the investment efficiency is lower, the price of sharing scenario is higher than the price of the independent investment. There are many reasons for this complex phenomenon, and two of them are the most obvious. On the one hand, maintaining a high level of technology investment efficiency can increase enterprise income, reduce unnecessary additional expenses, and meet the needs of business operations. However, when the investment efficiency level is low, sharing behavior helps to reduce its investment pressure and increase the benefits brought by technology. On the other hand, considering the effect of market expansion, the price is introduced to the market expansion effect. All in all, the price changes of the two scenarios are affected by the market size, income sharing ratio, and investment efficiency. In terms of price changes, the impact of investment efficiency is the most prominent.

Proposition 6 (Analysis of Shipping Market Effect) Considering the influence of blockchain technology on shipping market demand before and after sharing.

(a) For Port 1, the shipping market demand has the following changes:

a. When $m=1 / 4, \theta \in\left(0, \frac{105-9 \sqrt{97}}{44}\right)$ and $K>\frac{8}{9}, q_{1}^{I}<q_{1}^{S} ; \theta \in\left(\frac{105-9 \sqrt{97}}{44}, 1\right)$ and $K>$ $\frac{2(9-2 \theta) \theta}{(3-\theta)^{2}}, q_{1}^{I}<q_{1}^{S}$;

b. When $m=2 / 4, \theta \in\left(0, \frac{105-9 \sqrt{97}}{44}\right)$ and $K>\frac{8}{9}, q_{1}^{I}<q_{1}^{S} ; \theta \in\left(\frac{105-9 \sqrt{97}}{44}, 1\right)$ and $K>$ $\frac{2(9-2 \theta) \theta}{(3-\theta)^{2}}, q_{1}^{I}<q_{1}^{S}$

c. When $m=3 / 4, \theta \in\left(0, \frac{105-9 \sqrt{97}}{44}\right)$ and $K>\frac{8}{9}, q_{1}^{I}<q_{1}^{S} ; \theta \in\left(\frac{105-9 \sqrt{97}}{44}, 1\right)$ and $\frac{2(9-2 \theta) \theta}{(3-\theta)^{2}}<$ $K<\frac{2}{3}\left(1+\frac{18}{3-\theta}-\frac{10}{\theta}+\sqrt{\frac{20(5-7 \theta)}{\theta^{2}}+\frac{549-\theta(222-49 \theta)}{(3-\theta)^{2}}}\right), q_{1}^{I}>q_{1}^{S} ; \theta \in\left(\frac{105-9 \sqrt{97}}{44}, 1\right)$ and $K>$ $\frac{2}{3}\left(1+\frac{18}{3-\theta}-\frac{10}{\theta}+\sqrt{\frac{20(5-7 \theta)}{\theta^{2}}+\frac{549-\theta(222-49 \theta)}{(3-\theta)^{2}}}\right), q_{1}^{I}<q_{1}^{S}$

(b) For Port 2, the shipping market demand has the following changes:

a. When $m=1 / 4, \theta \in\left(0, \frac{105-9 \sqrt{97}}{44}\right)$ and $K>\frac{8}{9}, q_{2}^{I}>q_{2}^{S} ; \theta \in\left(\frac{105-9 \sqrt{97}}{44}, 1\right)$ and $K>$ $\frac{2(9-2 \theta) \theta}{(3-\theta)^{2}}, q_{2}^{I}>q_{2}^{S}$;

b. When $m=2 / 4, \theta \in\left(0, \frac{105-9 \sqrt{97}}{44}\right)$ and $K>\frac{8}{9}, q_{2}^{I}>q_{2}^{S} ; \theta \in\left(\frac{105-9 \sqrt{97}}{44}, 1\right)$ and $K>$ $\frac{2(9-2 \theta) \theta}{(3-\theta)^{2}}, q_{2}^{I}>q_{2}^{S}$;

c. When $m=3 / 4, \theta \in\left(0, \frac{105-9 \sqrt{97}}{44}\right)$ and $K>\frac{8}{9}, q_{2}^{I}>q_{2}^{S} ; \theta \in\left(\frac{105-9 \sqrt{97}}{44}, 1\right)$ and $K>$ $\frac{\sqrt{3600-5280 \theta+3256 \theta^{2}-824 \theta^{3}+289 \theta^{4}-60+44 \theta+7 \theta^{2}}}{3(3-\theta) \theta}, q_{2}^{I}>q_{2}^{S} ; \theta \in\left(\frac{105-9 \sqrt{97}}{44}, 1\right)$ and $\frac{18 \theta-4 \theta^{2}}{9-6 \theta+\theta^{2}}<K<$ $\frac{\sqrt{3600-5280 \theta+3256 \theta^{2}-824 \theta^{3}+289 \theta^{4}}-60+44 \theta+7 \theta^{2}}{3(3-\theta) \theta}, q_{2}^{I}<q_{2}^{S}$.

Proposition 6 shows the change of market demand in technology investment scenario and technology sharing scenario in the shipping market. It can be found that Proposition 6 (a) 
reflects the demand changes under different market expansion conditions. From the demand change of Port 1, it can be found that, no matter how the profit-sharing proportion changes, the demand of sharing scenario is higher than the Port 2's demand for independent blockchain technology scenarios regardless of the change in the profit-sharing ratio. However, when the market expansion ratio reaches a high level, the demand for Port 1 without sharing is higher than Port 2 with active technology sharing. The adoption of new technology will potentially increase its market demand, especially in the case of non-investment represented by Port 1, adopting technology sharing to increase its market demand. However, in the case of a high expansion ratio, the investment efficiency and share ratio will comprehensively affect the demand of Port 1. This change in demand has a substantial impact on investment efficiency. High-income sharing ratio and investment efficiency may lead Port 1 not to share market share, otherwise, it will reduce its revenue and market capacity. By observing Proposition 6 (b), we can find that the choice of market capacity of Port 2 is just opposite to Port 1. It's the result of the competition effect. Therefore, under the premise of certain market capacity, the optimal policy changes of the two ports in terms of demand are the opposite.

In summary, this paper analyzes the changes in the shipping market effect from two scenarios of blockchain technology investment and sharing. Thus, the economic effect of shipping enterprises can be obtained by synthesizing the above-market effects, as shown in Proposition 7 , which further explains the change of revenue in different ports.

\subsubsection{Economic Effects of Shipping Companies}

The above analysis examines the investment and sharing decisions in the competitive environment of ports from the perspective of the price and demand of the shipping market. This part combines the two and considers the economic effect of enterprises to obtain the optimal operation strategy. The specific analysis results are shown in Proposition 7.

Proposition 7 (Economic Effect Analysis of Shipping Market) Consider the economic impact of blockchain technology on shipping enterprises before and after sharing.

(a) For Port 1, there is an interactive relationship between investment efficiency and sharing parameters, that is to say, it is possible to find out the optimal selection strategy for Port 1 to choose investment efficiency and sharing parameters under different market expansion. The results are shown in Figure 3.

(b) For Port 2, there is an interactive relationship between investment efficiency and sharing parameters, that is to say, it is possible to find out the optimal selection strategy for Port 2 to choose investment efficiency and sharing parameters under different market expansion. The results are shown in Figure 4.

In Figure 3, we can find the optimal selection strategy of Port 1 in different expansion conditions. It can be found that the scope of shared scenarios will continue to decline with the market expansion, while the scope of investment scenario selection strategy increases. This way can increase the range of their investment. There are two management implications: On the one hand, Port 1 as a passive recipient of blockchain technology, or the party that actively provides profits to support Port 2's investment, and chooses the optimal operation scheme for itself according to the comprehensive influence of investment efficiency and profit sharing 
ratio; on the other hand, as far as the scenario of technology sharing is concerned, the different proportion of distribution ratio will affect Port 1 Strategy selection. According to the fixed income ratio, the optimal choice of Port 1 will change from investment to sharing, and then to investment. This is determined by investment efficiency. The higher the investment efficiency, the more favorable for Port 1; When the investment efficiency is lower, Port 1 turns to support the blockchain technology investment of Port 2. Therefore, for Port 1, the passive consideration of the use of blockchain technology is limited to the investment efficiency of Port 2, and it is important to choose a reasonable operation strategy.

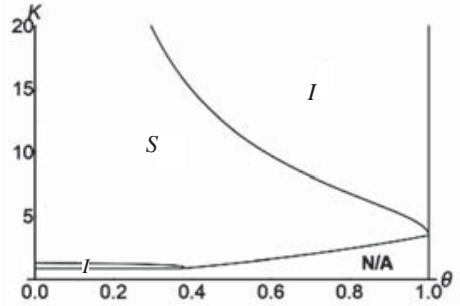

(a) $m=1 / 4$

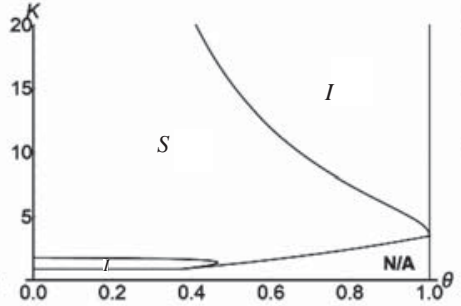

(b) $m=2 / 4$

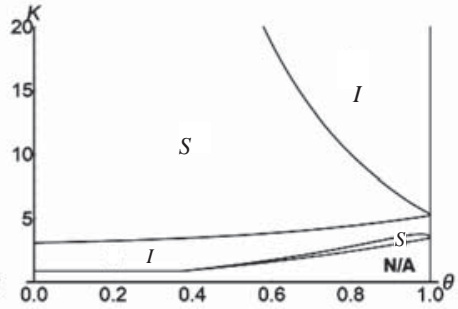

(c) $m=3 / 4$

Figure 3 Port 1 optimal strategy

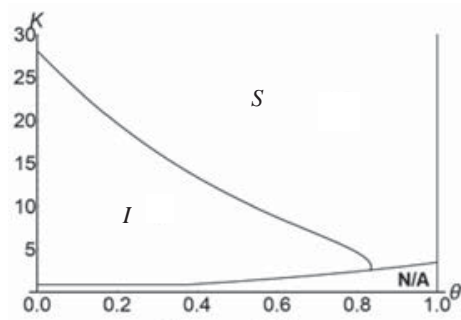

(a) $m=1 / 4$

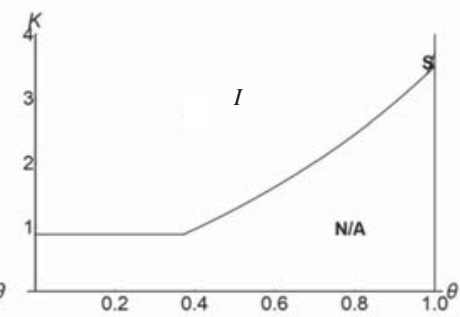

(b) $m=2 / 4$

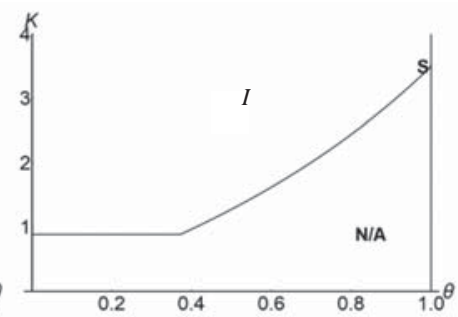

(c) $m=3 / 4$

Figure 4 Port 2 optimal strategy

In Figure 4, we can find the optimal strategy for Port 2. Among them, the choice of Port 2 is more direct than Port 1 , that is, there are a more clear investment and sharing areas. When the market expansion ratio is low, Port 2 will have more choices when choosing the sharing strategy than the investment situation; when the market expansion reaches a medium-to-high level, the investment strategy is the optimal choice. The resulting management enlightenment: Port 2 chooses its technology investment and sharing operation strategy according to the potential market expansion brought by technology. When the market expansion level is low, the investment strategy can play a role in sharing the investment cost; when the level is high, its investment can drive the enterprise to obtain a larger potential market. In a competitive environment, gaining a high number of market capacity will increase the profits of enterprises. Therefore, for Port 1, it is often the best choice to make use of the benefits from its investment. The optimal strategies are considered from Port 1 and Port 2 respectively. The equilibrium strategy of investment and shared operation of two ports can be obtained by considering the two factors comprehensively. The results are shown in Proposition 8. 
Proposition 8 (Equilibrium Strategy Based on Economic Effect) Consider the optimal investment and sharing operation strategy of blockchain technology from the perspective of economic effect.

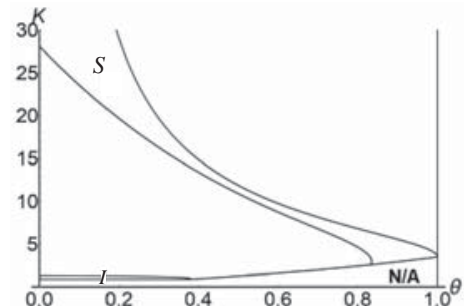

(a) $m=1 / 4$

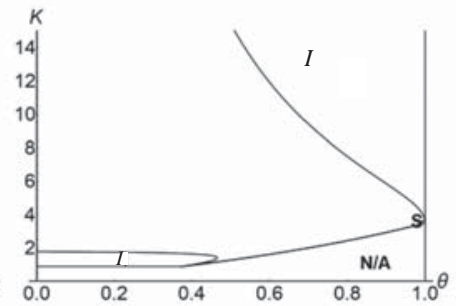

(b) $m=2 / 4$

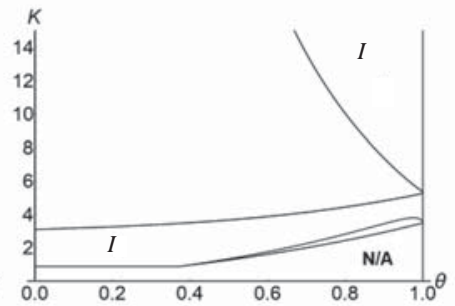

(c) $m=3 / 4$

Figure 5 Equilibrium strategy selection of dual-port operation

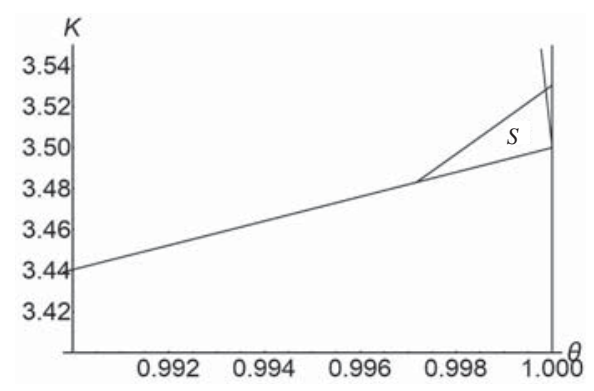

Figure 6 Dual-port equilibrium strategy

Considering the economic effects of the two ports, the optimal investment scheme can be obtained, that is to say, when the investment efficiency and sharing parameters meet different combinations of conditions, they will have a positive impact on the income of the two ports, which is the optimal choice of investment strategy (as shown in Figure 5).

Figure 5 shows the equilibrium strategy selection of the two ports in a competitive environment. Among them, it can be found in Figure 5 that the range of policy selection in different operation strategies is different. With the expansion of the market, the use of the blockchain investment scheme occupies a dominant position. We can get the analysis results of Figure 6 after zooming in Figure 5(c). It can be found that the investment scheme of blockchain technology can make the two ports achieve the optimal selection state. When satisfying the low-level market expansion, regardless of changes in investment efficiency, Port 2 adopts a technology sharing strategy to obtain maximum public benefits, make up for its costs, and bring external benefits to Port 1 . However, when the market capacity of Port 2 expands to a medium or high level, Port 2's technology sharing will gradually reduce Port 1's revenue, and it is optimal when it still maintains a high sharing ratio and relatively efficient investment efficiency. However, in the actual business activities, such extreme situations are rarely found (except for highly centralized alliance enterprise groups). Therefore, the strategy of adopting technology investment is a common state, that is to say, in competitive business activities, the positive impact of technology spillover is often considered by non-investors. For direct technology investors, the 
performance of their returns is often the direct benefits. Therefore, in the actual management activities, it is necessary to consider the actual benefits brought by technology investment, such as the expansion of market scope, the improvement of technical efficiency, or the decrease of cost. After careful evaluation, a reasonable selection strategy is formed. Finally, by finding out the change and invariance in business, we can get the equilibrium strategy choice in a competitive environment.

\section{Port Competitiveness: Robust Analysis}

In the basic discussion, we set the intensity of the competition coefficient $b$ as $b=1$, and discuss the market and economic effect under different parameter conditions. From the change of competition intensity $b$, this part discusses the equilibrium scheme of port blockchain technology investment and sharing strategy in different combinations of conditions, to test the stability of the conclusion. According to the above discussion, we consider the competition coefficient strength $b$ as $b=1 / 4, b=2 / 4$ and $b=3 / 4$, respectively. On this basis, considering the blockchain technology investment and sharing strategy when $m$ is $m=1 / 4, m=2 / 4$ and $m=3 / 4$, respectively. Then, it gives a balanced choice of port economic effects (as shown in Figure 7).

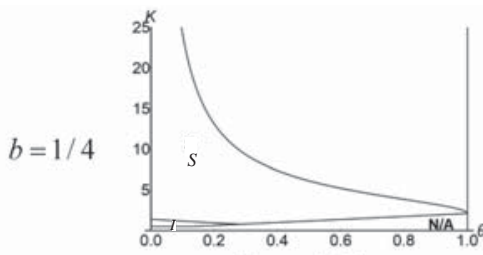

(a) $m=1 / 4$

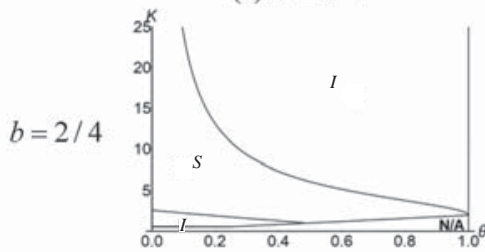

(d) $m=1 / 4$

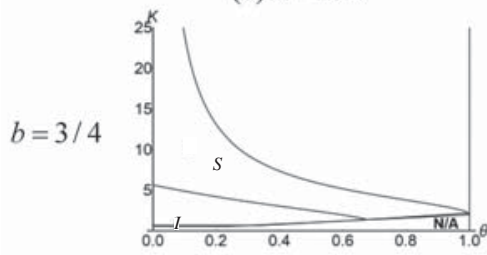

(g) $m=1 / 4$

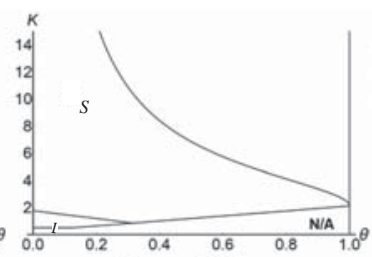

(b) $m=2 / 4$

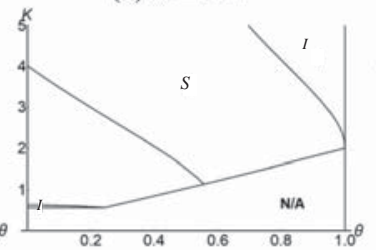

(e) $m=2 / 4$

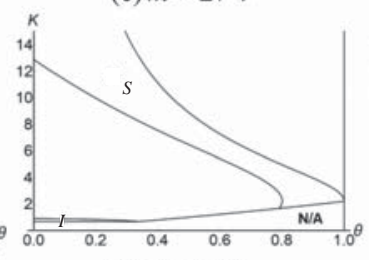

(h) $m=2 / 4$

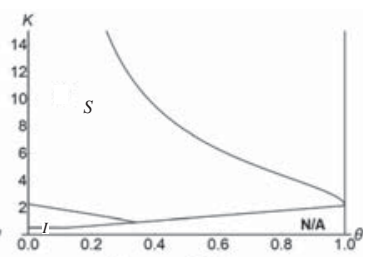

(c) $m=3 / 4$

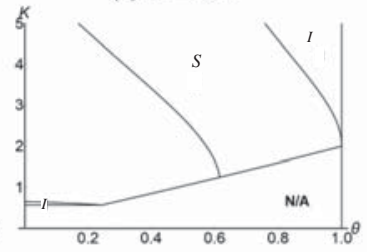

(f) $m=3 / 4$

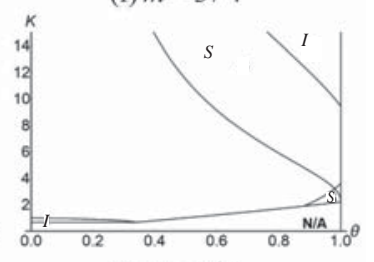

(i) $m=3 / 4$

Figure 7 Dual-port equilibrium strategy

Figure 7 shows the equilibrium strategy results of technology investment and operation of dual-port blockchain under different competition parameters. It was found that under different changing conditions of competition intensity, the result performance is similar to the basic discussion. The results show that the intensity of competition has an impact on the technology investment and sharing strategy of dual ports, but the choice of equilibrium strategy will not be 
greatly affected. The management enlightenment: On the one hand, in the environment of port competition, the impact of the equilibrium strategy of blockchain technology investment and sharing will be affected by the fierce competition. It only changes the combination of conditions for strategy selection. Therefore, in the actual business operation, port enterprises should take into account the fierce competition of existing industries and adjust their business activities in different competitive environments. On the other hand, considering the combination of different factors, dual ports need to consider their purposes and choose different advantageous strategies comprehensively. The key point is that low-tech investment efficiency is the best choice of sharing strategy; high-tech efficiency is selected as an investment to obtain the spillover effect brought by the investment effect, to satisfy the purpose of both ports to obtain a balanced income.

\section{Conclusion}

\subsection{Concluding Remarks and Main Findings}

In a competitive environment, the investment and operation of ports are still controversial. It's also one of the reasons why blockchain technology cannot be widely implemented. What kind of operation strategy affects itself and its competitors? Is the investment strategy optimal? Or the sharing strategy? The paper analyzes the port competition in a competitive environment. Specifically, the paper is divided into two discussion stages, which respectively investigate the equilibrium strategy after the blockchain technology investment, and analyze the technology sharing problem after the blockchain technology investment. In the first stage of the discussion, from the perspective of port investment efficiency, the paper examines the impact of investment efficiency on the decision-making of whether to introduce blockchain technology into the port and analyzes the market effect after the investment and finally obtains the equilibrium strategy to meet the profit of dual ports. Then, in the second stage of discussion, we consider the technology sharing strategy when the investment conditions are satisfied. It is found that when the investment efficiency of Port 2 is high and the market expansion level of Port 2 is low, the dual-port adopts the investment blockchain technology as the equilibrium strategy; When the technical investment efficiency meets the low efficiency, the sharing strategy can solve the problem of large investment cost. Finally, to verify the stability of the existing research results, the paper considers the change of competitive intensity and verifies the stability of the results in the basic discussion. Through the above analysis, we give relevant management suggestions.

\subsection{Management Implication and Future Research}

The following management enlightenment: On the one hand, technology investment will have different results in a competitive environment, especially under the influence of investment efficiency, it will produce a great deviation in equilibrium choice. In the actual business investment model, it is necessary to pay attention to the issue of technology investment efficiency. Therefore, the port should set a reasonable efficiency target value when investing in blockchain technology. On the other hand, blockchain is an integration method different from information technology, it helps to strengthen the degree of credibility in data exchange. The potential assumption of this paper is that the sharing of blockchain technology can help to 
enhance the potential revenue of port enterprises, but the receiver will also pay a part of the funds to support construction. Therefore, the choice of sharing behavior should consider the factors of revenue to meet the balanced operation of dual ports.

Our model focuses on the potential strategy selection of dual ports in blockchain technology investment and sharing under a competitive environment, and aims to focus on the market and economic effect in different scenarios. Although the investment and sharing problems of blockchain technology are examined from the perspective of efficiency, in essence, the impact of the factors that affect efficiency on blockchain technology is not investigated. Therefore, the analysis from the efficiency will promote the technology investment and sharing of blockchain. In addition, this paper discusses the technology investment of blockchain in a competitive environment. However, as a new technology, blockchain has not been used on a large scale. The potential reason is that the benefits brought by blockchain cannot be well-reflected. Therefore, examining the impact on the port supply chain from the perspective of revenue management is also a potential research direction in the future.

\section{References}

[1] Helo P, Hao Y. Blockchains in operations and supply chains: A model and reference implementation. Computers \& Industrial Engineering, 2019, 136: 242-251.

[2] Casino F, Dasaklis T K, Patsakis C. A systematic literature review of blockchain-based applications: Current status, classification and open issues. Telematics and Informatics, 2019, 36: 55-81.

[3] Pournader M, Shi Y, Seuring S, et al. Blockchain applications in supply chains, transport and logistics: A systematic review of the literature. International Journal of Production Research, 2020, 58(7): 2063-2081.

[4] Saberi S, Kouhizadeh M, Sarkis J, et al. Blockchain technology and its relationships to sustainable supply chain management. International Journal of Production Research, 2019, 57(7): 2117-2135.

[5] Hughes L, Dwivedi Y K, Misra S K, et al. Blockchain research, practice and policy: Applications, benefits, limitations, emerging research themes and research agenda. International Journal of Information Management, 2019, 49: 114-129.

[6] Yang C S. Maritime shipping digitalization: Blockchain-based technology applications, future improvements, and intention to use. Transportation Research Part E: Logistics and Transportation Review, 2019, 131: $108-117$.

[7] Clott C, Hartman B, Beidler B. Sustainable blockchain technology in the maritime shipping industry. Maritime Supply Chains, 2020: 207-228.

[8] Liu P, Yi S P. A study on supply chain investment decision-making and coordination in the Big Data environment. Annals of Operations Research, 2018, 270(1-2): 235-253.

[9] Salmani Y, Partovi F Y, Banerjee A. Customer-driven investment decisions in existing multiple sales channels: A downstream supply chain analysis. International Journal of Production Economics, 2018, 204: $44-58$.

[10] Cui L, Deng J, Liu F, et al. Investigation of RFID investment in a single retailer two-supplier supply chain with random demand to decrease inventory inaccuracy. Journal of Cleaner Production, 2017, 142: 2028-2044.

[11] Chiang C Y, Hanna M, Liu Z, et al. Obtaining collaboration benefits: The role of collaboration-specific investment and absorptive capacity in China. Operations Management Research, 2018, 11(3-4): 69-82.

[12] Saberi S, Cruz J M, Sarkis J, et al. A competitive multiperiod supply chain network model with freight carriers and green technology investment option. European Journal of Operational Research, 2018, 266(3): 934-949.

[13] Lu Q, Xu X. Adaptable blockchain-based systems: A case study for product traceability. IEEE Software. 2017, 34(6): 21-27.

[14] Sander F, Semeijn J, Mahr D. The acceptance of blockchain technology in meat traceability and transparency. British Food Journal, 2018, 120(9): 2066-2079. 
[15] Choi T M. Blockchain-technology-supported platforms for diamond authentication and certification in luxury supply chains. Transportation Research Part E: Logistics and Transportation Review, 2019, 128: $17-29$.

[16] Zhu Q, Kouhizadeh M. Blockchain technology, supply chain information, and strategic product deletion management. IEEE Engineering Management Review, 2019, 47(1): 36-44.

[17] Civelek M E, Özalp A. Blockchain technology and final challenge for paperless foreign trade. Eurasian Academy of Sciences Eurasian Business \& Economics Journal, 2018, 15: 1-8.

[18] Chang S E, Chen Y C, Lu M F. Supply chain re-engineering using blockchain technology: A case of smart contract based tracking process. Technological Forecasting and Social Change, 2019, 144: 1-11.

[19] Choi T M, Feng L, Li R. Information disclosure structure in supply chains with rental service platforms in the blockchain technology era. International Journal of Production Economics, 2020, 221: 107-473.

[20] Yang C S. Maritime shipping digitalization: Blockchain-based technology applications, future improvements, and intention to use. Transportation Research Part E: Logistics and Transportation Review, 2019, 131: $108-117$.

[21] Lambourdiere E, Corbin E. Blockchain and maritime supply-chain performance: Dynamic capabilities perspective. Worldwide Hospitality and Tourism Themes, 2020, 12(1): 24-34.

[22] Yan Y, Zhao R, Chen H. Prisoner's dilemma on competing retailers' investment in green supply chain management. Journal of Cleaner Production, 2018, 184: 65-81.

[23] Lai X, Tao Y, Wang F, et al. Sustainability investment in maritime supply chain with risk behavior and information sharing. International Journal of Production Economics, 2019, 218: 16-29.

[24] Parast M M. The impact of R\&D investment on mitigating supply chain disruptions: Empirical evidence from US firms. International Journal of Production Economics, 2020, 227: 107-671.

[25] Dong C, Liu Q, Shen B. To be or not to be green? Strategic investment for green product development in a supply chain. Transportation Research Part E: Logistics and Transportation Review, 2019, 131: 193-227.

[26] Lin Z, Wang S, Yang L. Motivating innovation alliance's environmental performance through eco-innovation investment in a supply chain. Journal of Cleaner Production, 2020, 23: 122-361.

[27] Hafezalkotob A. Competition, cooperation, and coopetition of green supply chains under regulations on energy saving levels. Transportation Research Part E: Logistics and Transportation Review, 2017, 97: 228-250.

[28] Jena S K, Meena P L. Price and service competition in a tourism supply chain. Service Science, 2019, 11(4): $279-291$.

[29] Liu J, Wang J. Carrier alliance incentive analysis and coordination in a maritime transport chain based on service competition. Transportation Research Part E: Logistics and Transportation Review, 2019, 128: 333-355.

[30] Li M, Zhang X, Dan B. Competition and cooperation in a supply chain with an offline showroom under asymmetric information. International Journal of Production Research, 2019, 10: 1-6.

[31] Wang C, Yang H, Yang D. The influence of third-party e-commerce platform price limits on the dual-channel strategy of manufacturers. Journal of Systems Science and Information, 2019, 7(2): 173-186.

[32] Chen S, Chen X, Jing Y. On the competitive mechanism concerning the third-party transaction in Chinese market. Journal of Systems Science and Information, 2020, 8(1): 33-52.

[33] Seo Y J, Dinwoodie J, Roe M. The influence of supply chain collaboration on collaborative advantage and port performance in maritime logistics. International Journal of Logistics Research and Applications, 2016, 19(6): $562-582$.

[34] Song Z, Tang W, Zhao R. Cooperation mode for a liner company with heterogeneous ports: Business cooperation vs. port investment. Transportation Research Part E: Logistics and Transportation Review, 2018, 118(3): 513-533.

[35] Xing W, Liu Q, Chen G. Pricing strategies for port competition and cooperation. Maritime Policy \& Management, 2018, 45(2): 260-277.

[36] Wu S, Yang Z. Analysis of the case of port co-operation and integration in Liaoning (China). Research in Transportation Business \& Management, 2018, 26(2): 18-25.

[37] Wang C, Xie F, Xu L. Which terminals should expand investment: A perspective of internal non-cooperative competition in a port? Maritime Policy \& Management, 2020, 17(1): 1-18.

[38] Cui H, Notteboom T. A game theoretical approach to the effects of port objective orientation and ser- 
vice differentiation on port authorities' willingness to cooperate. Research in Transportation Business \& Management, 2018, 26: 76-86.

[39] Chen S, Chen X, Jing Y. On the Competitive Mechanism Concerning the Third-Party Transaction in Chinese Market. Journal of Systems Science and Information. 2020, 8(1): 33-52.

[40] Martinez V, Zhao M, Blujdea C, et al. Blockchain-driven customer order management. International Journal of Operations \& Production Management, 2019, 39(6-8): 993-1022.

[41] Yang X, Cai G, Ingene C A, et al. Manufacturer Strategy on Service Provision in Competitive Channels. Production and Operations Management, 2020, 29(1): 72-89.

\section{Appendix}

\section{Appendix A. Equilibrium Solution Result} $\frac{a}{2+b}$.

1) Basic scenario: $\pi_{1}^{\mathrm{NA}}=\frac{a^{2}}{(2+b)^{2}} ; \pi_{2}^{\mathrm{NA}}=\frac{a^{2}}{(2+b)^{2}} ; q_{1}^{\mathrm{NA}}=\frac{a}{2+b} ; q_{2}^{\mathrm{NA}}=\frac{a}{2+b} ; p_{1}^{\mathrm{NA}}=\frac{a}{2+b} ; p_{2}^{\mathrm{NA}}=$

2) Investment scenario:

$$
\begin{aligned}
& \pi_{1}^{I}=\frac{a^{2}\left(4-K(2-b-b m)\left(4-b^{2}\right)\right)^{2}}{\left(\left(4-b^{2}\right)^{2} K-8\right)^{2}} ; \quad \pi_{2}^{I}=\frac{a^{2} K(b-2(1+m))^{2}}{\left(4-b^{2}\right)^{2} K-8} ; \\
& p_{1}^{I}=\frac{a\left(K(2-b-b m)\left(4-b^{2}\right)-4\right)}{\left(4-b^{2}\right)^{2} K-8} ; \quad p_{2}^{I}=\frac{a K(2(1+m)-b)\left(4-b^{2}\right)}{\left(4-b^{2}\right)^{2} K-8} ; \\
& q_{1}^{I}=\frac{a\left(K(2-b-b m)\left(4-b^{2}\right)-4\right)}{\left(4-b^{2}\right)^{2} K-8} ; \quad q_{2}^{I}=\frac{a K\left(4-b^{2}\right)(2(1+m)-b)}{\left(4-b^{2}\right)^{2} K-8} ; \\
& e^{I}=\frac{4 a(2(1+m)-b)}{\left(4-b^{2}\right)^{2} K-8} .
\end{aligned}
$$

3) Blockchain investment and sharing scenario:

$$
\begin{aligned}
\pi_{1}^{S}= & \frac{a^{2}(1-\theta)(4+8 K+8 m+b(-4 K(1+m)+b K(-2+b+b m)(1+\theta)-(1+2 m)(4+b \theta)))^{2}}{\left(8(-1+2 K-4 \theta)+b\left(16(1+\theta)+b\left(-8+2 \theta(1+4 \theta-2 b(1+\theta))+K(1+\theta)\left(-8+b^{2}(1+\theta)\right)\right)\right)^{2}\right.} \\
& a^{2}\left(-\theta(1+2 m)^{2}\left(4-b^{2} \theta\right)+\right. \\
\pi_{2}^{S}= & \frac{\left.2 K\left((b-2(1+m))^{2}+(4-b(1+m)(4+b(1-b+m))) \theta+b^{2}(-1+b+b m) \theta^{2}\right)\right)}{2\left(8(-1+2 K-4 \theta)+b\left(16(1+\theta)+b\left(-8+2 \theta(1+4 \theta-2 b(1+\theta))+K(1+\theta)\left(-8+b^{2}(1+\theta)\right)\right)\right)\right.} \\
p_{1}^{S}= & \frac{a(-4+8 K-16 \theta-4 b(-2+K(1+m)-\theta(3+2 m))+}{8(-1+2 K-4 \theta)+b\left(16(1+\theta)+b\left(-8+2 \theta(1+4 \theta-2 b(1+\theta))-K(1+\theta)\left(8-b^{2}(1+\theta)\right)\right)\right)} \\
p_{2}^{S}= & \frac{a\left(K(-2+b-2 m+b(-1+b+b m) \theta)\left(b^{2}(1+\theta)-4\right)-\theta(1+2 m)(8-b(2-b)(2+b \theta))\right)}{8(-1+2 K-4 \theta)+b\left(16(1+\theta)+b\left(-8+2 \theta(1+4 \theta-2 b(1+\theta))+K(1+\theta)\left(b^{2}(1+\theta)-8\right)\right)\right)} \\
q_{1}^{S}= & \frac{a\left(K(2-b-b m)\left(4-b^{2}(1+\theta)\right)-(4-b(4+b) \theta)(1-2(1+m) \theta)\right)}{-8+2 b(8+b) \theta-4 b(-4+b(2+b)) \theta^{2}-4\left(8+b^{3}\right) \theta^{3}+8 b^{2} \theta^{4}+K\left(-4+b^{2}(1+\theta)\right)^{2}} \\
q_{2}^{S}= & \frac{a\left(4-b^{2}(1+\theta)\right)\left(K(2-b+2 m-b \theta)+2 \theta^{2}(1-2(1+m) \theta)\right)}{-8+2 b(8+b) \theta-4 b(-4+b(2+b)) \theta^{2}-4\left(8+b^{3}\right) \theta^{3}+8 b^{2} \theta^{4}+K\left(-4+b^{2}(1+\theta)\right)^{2}} \\
e^{S}= & \frac{a\left(8(1+m+2 \theta)+b\left(4 b-4(3+2 m)(1+\theta)+b^{2}(3+2 m) \theta(1+\theta)-2 b \theta(1+m+2 \theta)\right)\right)}{8(-1+2 K-4 \theta)+b\left(16(1+\theta)+b\left(2 \theta(1+4 \theta-2 b(1+\theta)-8)+K(1+\theta)\left(b^{2}(1+\theta)-8\right)\right)\right)}
\end{aligned}
$$




\section{Appendix B. The Resulting Proof of Technology Investment Scenario}

This section explains the calculation process of basic results with technology investment scenarios. First of all, based on the description of the decision sequence of the text, we determine the terminal demand of the shipping market, and then determine the Port 2 blockchain technology input level, and finally reverse the price and income based on the calculation results. Specifically, we can get $p_{1}^{I}=a-q_{1}^{I}-b q_{2}^{I}$ and $p_{2}^{I}=(1+m) a-q_{2}^{I}-b q_{1}^{I}+e^{I}$ from $\pi_{1}^{I}=p_{1}^{I} q_{1}^{I}$ and $\pi_{2}^{I}=p_{2}^{I} q_{2}^{I}-\frac{K}{2}\left(e^{I}\right)^{2}$. Then solve the first and second derivatives of profit, which is $\frac{\partial \pi_{1}^{I}}{\partial q_{1}^{I}}=a-2 q_{1}^{I}-b q_{2}^{I}$ and $\frac{\partial \pi_{2}^{I}}{\partial q_{2}^{I}}=a+e^{I}+a m-b q_{1}^{I}-2 q_{2}^{I}$. In addition, the result of solving the Hessian matrix of its two elements is greater than 0. By combining the above two formulas, we can get $q_{1}^{I}=\frac{a(2-b-b m)-b e^{I}}{4-b^{2}}, q_{2}^{I}=\frac{a(2(1+m)-b)-2 e^{I}}{4-b^{2}}, p_{1}^{I}=\frac{a(2-b-b m)-b e^{I}}{4-b^{2}}$, $p_{2}^{I}=\frac{a(2(1+m)-b)-2 e^{I}}{4-b^{2}}, \pi_{2}^{I}=p_{2}^{I} q_{2}^{I}-\frac{K}{2}\left(e^{I}\right)^{2}$. Determine the first and second derivatives of the input level as $\frac{\partial \pi_{2}^{I}}{\partial e^{I}}=-e^{I} K+\frac{8 e^{I}+a(8-4 b+8 m)}{\left(4-b^{2}\right)^{2}}$ and $\frac{\partial^{2} \pi_{2}^{I}}{\partial\left(e^{I}\right)^{2}}=\frac{8}{\left(4-b^{2}\right)^{2}}-K$. The investment level should be the largest, so $K>\frac{8}{16-8 b^{2}+b^{4}}$. In this way, the optimal input can be obtained $e^{I}=\frac{4 a(2(1+m)-b)}{\left(4-b^{2}\right)^{2} K-8}$. Finally, bring it back to other expressions to get the following results: $\pi_{1}^{I}=\frac{a^{2}\left(4-K(2-b-b m)\left(4-b^{2}\right)\right)^{2}}{\left(\left(4-b^{2}\right)^{2} K-8\right)^{2}} ; \pi_{2}^{I}=\frac{a^{2} K(b-2(1+m))^{2}}{\left(4-b^{2}\right)^{2} K-8} ; p_{1}^{I}=\frac{a\left(K(2-b-b m)\left(4-b^{2}\right)-4\right)}{\left(4-b^{2}\right)^{2} K-8}$; $p_{2}^{I}=\frac{a K(2(1+m)-b)\left(4-b^{2}\right)}{\left(4-b^{2}\right)^{2} K-8} ; q_{1}^{I}=\frac{a\left(K(2-b-b m)\left(4-b^{2}\right)-4\right)}{\left(4-b^{2}\right)^{2} K-8} ; q_{2}^{I}=\frac{a K\left(4-b^{2}\right)(2(1+m)-b)}{\left(4-b^{2}\right)^{2} K-8}$.

\section{Appendix C. Proof of Propositions}

Proof of Proposition 1 By comparing the effect of shipping price, we can get the price change of the first stage:

Consider price changes from the perspective of Port 1. Comparing the price of Port 1 after investment with that before investment:

$$
p_{1}^{I}-p_{1}^{\mathrm{NA}}=\frac{a\left(K(2-b-b m)\left(4-b^{2}\right)-4\right)}{\left(4-b^{2}\right)^{2} K-8}-\frac{a}{2+b}<0
$$

and $K>\frac{8}{\left(4-b^{2}\right)^{2}}$.

Compare the shipping market price before and after Port 2 investment:

$$
p_{2}^{I}-p_{2}^{\mathrm{NA}}=\frac{a K(2(1+m)-b)\left(4-b^{2}\right)}{\left(4-b^{2}\right)^{2} K-8}-\frac{a}{2+b}>0,
$$

and $K>\frac{8}{\left(4-b^{2}\right)^{2}}$.

Proof of Proposition 2 Proposition 2 reflects the change in shipping market demand. By obtaining the calculation results, we can compare the demand changes of the two ports. Specifically, from the perspective of Port 1, we can get the following conclusions:

$$
q_{1}^{I}-q_{1}^{\mathrm{NA}}=\frac{a\left(K(2-b-b m)\left(4-b^{2}\right)-4\right)}{\left(4-b^{2}\right)^{2} K-8}-\frac{a}{2+b}<0
$$

and $K>\frac{8}{\left(4-b^{2}\right)^{2}}$.

Comparing the shipping market price of Port 2 before and after investment:

$$
q_{2}^{I}-q_{2}^{\mathrm{NA}}=\frac{a K\left(4-b^{2}\right)(2(1+m)-b)}{\left(4-b^{2}\right)^{2} K-8}-\frac{a}{2+b}>0,
$$


and $K>\frac{8}{\left(4-b^{2}\right)^{2}}$.

Proof of Proposition 3 Proposition 3 reflects the income of enterprises in the shipping market. By comparing the profit of each port before and after investment, we can get the optimal strategy of each port before and after investment. Specifically, from the perspective of Port 1, we can get:

$$
\pi_{1}^{I}-\pi_{1}^{\mathrm{NA}}=\frac{a^{2}\left(4-K(2-b-b m)\left(4-b^{2}\right)\right)^{2}}{\left(\left(4-b^{2}\right)^{2} K-8\right)^{2}}-\frac{a^{2}}{(2+b)^{2}} .
$$

When $\pi_{1}^{I}-\pi_{1}^{\mathrm{NA}}>0, \frac{8}{\left(4-b^{2}\right)^{2}}<K<\frac{4(4+b)}{(2-b)(2+b)^{2}(4-b(2+m))}$; When $\pi_{1}^{I}-\pi_{1}^{\mathrm{NA}}<0, K>$ $4(4+b)$

$\overline{(2-b)(2+b)^{2}(4-b(2+m))}$.

For Port 2, we can get the following results by comparing the income before and after the blockchain technology investment:

$$
\pi_{2}^{I}-\pi_{2}^{\mathrm{NA}}=\frac{a^{2} K(b-2(1+m))^{2}}{\left(4-b^{2}\right)^{2} K-8}-\frac{a^{2}}{(2+b)^{2}}>0,
$$

and $K>\frac{8}{\left(4-b^{2}\right)^{2}}$.

Proof of Proposition 4 Based on the results of Proposition 3, we can find that when Port 1 satisfies the optimal investment, the optimal choice interval of Port 2's investment efficiency is $K>\frac{8}{\left(4-b^{2}\right)^{2}}$; That is to say, when $\frac{8}{\left(4-b^{2}\right)^{2}}<K<\frac{4(4+b)}{(2-b)(2+b)^{2}(4-b(2+m))}$, it can meet the common optimal choice of two ports under the condition of blockchain technology investment, and finally reach the equilibrium state. In addition, when investment efficiency meets $K>$ $\frac{4(4+b)}{(2-b)(2+b)^{2}(4-b(2+m))}$, the income of Port 2 is better than that of Port 2 before investment, but the optimal choice of Port 1 is no investment scenario. When $K>\frac{4(4+b)}{(2-b)(2+b)^{2}(4-b(2+m))}$, Port 2 is optimal, and equilibrium strategy cannot be formed at this time.

Proof of Proposition 5 Proposition 5 reflects the change in the shipping market price. Among them, from the perspective of the market price of each port, the relationship between shipping price before and after technology sharing is considered. In addition, it should be noted that in the second stage of the discussion, we need to increase the discussion of market expansion ratio $m$. In the basic discussion, the parameter of competition intensity is $b=1$. The following takes Port 1 as an example to illustrate the process of price change.

From the original calculation results, we get $p_{1}^{I}=\frac{a\left(K(2-b-b m)\left(4-b^{2}\right)-4\right)}{\left(4-b^{2}\right)^{2} K-8}$ and $p_{1}^{S}=\frac{a\left(-4+8 K-16 \theta-4 b(-2+K(1+m)-\theta(3+2 m))+b^{3}(1+\theta)(K(1+m)-\theta(3+2 m))+b^{2}\left(-4+\theta+4 \theta^{2}-2 K(1+\theta)\right)\right)}{8(-1+2 K-4 \theta)+b\left(16(1+\theta)+b\left(-8+2 \theta(1+4 \theta-2 b(1+\theta))-K(1+\theta)\left(8-b^{2}(1+\theta)\right)\right)\right)}$.

Therefore, we can get the price changes before and after sharing. First of all, we need to consider the value range of investment efficiency. From the original calculation, we can get the restriction conditions of investment scenario and sharing scenario on efficiency respectively: $K>$ $\frac{8}{16-8 b^{2}+b^{4}}$ and $K>\frac{8+32 \theta+2 b(-8(1+\theta)+b(4-\theta(1+4 \theta-2 b(1+\theta))))}{\left(4-b^{2}(1+\theta)\right)^{2}}$. Because the competition intensity parameter is $b=1$, we can get $K>\frac{8}{9}$ and $K>\frac{8+32 \theta+2(4-8(1+\theta)-\theta(1+4 \theta-2(1+\theta)))}{(3-\theta)^{2}}$. When $\frac{8}{9}-\frac{8+32 \theta+2(4-8(1+\theta)-\theta(1+4 \theta-2(1+\theta)))}{(3-\theta)^{2}}>0,0<\theta<\frac{3}{44}(35-3 \sqrt{97}) ;$ When

$$
\frac{8}{9}-\frac{8+32 \theta+2(4-8(1+\theta)-\theta(1+4 \theta-2(1+\theta)))}{(3-\theta)^{2}}<0, \quad \frac{3}{44}(35-3 \sqrt{97})<\theta<1 .
$$


When $m=1 / 4$ and $0<\theta<\frac{3}{44}(35-3 \sqrt{97})$, compare price changes before and after technology sharing:

$$
\begin{aligned}
& p_{1}^{I}-p_{1}^{S}=\frac{a\left(K(2-b-b m)\left(4-b^{2}\right)-4\right)}{\left(4-b^{2}\right)^{2} K-8} \\
& a(-4+8 K-16 \theta-4 b(-2+K(1+m)-\theta(3+2 m))+ \\
& -\frac{\left.b^{3}(1+\theta)(K(1+m)-\theta(3+2 m))+b^{2}\left(-4+\theta+4 \theta^{2}-2 K(1+\theta)\right)\right)}{8(-1+2 K-4 \theta)+b(16(1+\theta)+}<0 . \\
& \left.b\left(-8+2 \theta(1+4 \theta-2 b(1+\theta))-K(1+\theta)\left(8-b^{2}(1+\theta)\right)\right)\right)
\end{aligned}
$$

When $m=2 / 4$ and $0<\theta<\frac{3}{44}(35-3 \sqrt{97})$, compare price changes before and after technology sharing:

$$
\begin{aligned}
p_{1}^{I}-p_{1}^{S}= & \frac{a\left(K(2-b-b m)\left(4-b^{2}\right)-4\right)}{\left(4-b^{2}\right)^{2} K-8} \\
& a(-4+8 K-16 \theta-4 b(-2+K(1+m)-\theta(3+2 m))+ \\
- & \frac{\left.b^{3}(1+\theta)(K(1+m)-\theta(3+2 m))+b^{2}\left(-4+\theta+4 \theta^{2}-2 K(1+\theta)\right)\right)}{8(-1+2 K-4 \theta)+b(16(1+\theta)+b(-8+2 \theta(1+4 \theta-2 b(1+\theta))-}<0 . \\
& \left.\left.K(1+\theta)\left(8-b^{2}(1+\theta)\right)\right)\right)
\end{aligned}
$$

When $m=3 / 4$ and $0<\theta<\frac{3}{44}(35-3 \sqrt{97})$, compare price changes before and after technology sharing:

$$
\begin{aligned}
p_{1}^{I}-p_{1}^{S}= & \frac{a\left(K(2-b-b m)\left(4-b^{2}\right)-4\right)}{\left(4-b^{2}\right)^{2} K-8} \\
& \frac{a(-4+8 K-16 \theta-4 b(-2+K(1+m)-\theta(3+2 m))+}{8(-1+2 K-4 \theta)+b(16(1+\theta)+} \\
\left.b\left(-8+2 \theta(1+4 \theta-2 b(1+\theta))-K(1+\theta)\left(8-b^{2}(1+\theta)\right)\right)\right) & \left.b^{3}(1+\theta)(K(1+m)-\theta(3+2 m))+b^{2}\left(-4+\theta+4 \theta^{2}-2 K(1+\theta)\right)\right)
\end{aligned}
$$

Based on the above comparison, we can find that the expansion ratio of the investment market will not affect the price changes. When $\theta \in\left(0, \frac{105-9 \sqrt{97}}{44}\right)$ and $K>\frac{8}{9}, p_{1}^{I}<p_{1}^{S}$.

Finally, when $m=1 / 4$ and $\frac{3}{44}(35-3 \sqrt{97})<\theta<1$, compare price changes before and after technology sharing:

$$
\begin{aligned}
& p_{1}^{I}-p_{1}^{S}=\frac{a\left(K(2-b-b m)\left(4-b^{2}\right)-4\right)}{\left(4-b^{2}\right)^{2} K-8} \\
& a(-4+8 K-16 \theta-4 b(-2+K(1+m)-\theta(3+2 m))+ \\
& -\frac{\left.b^{3}(1+\theta)(K(1+m)-\theta(3+2 m))+b^{2}\left(-4+\theta+4 \theta^{2}-2 K(1+\theta)\right)\right)}{8(-1+2 K-4 \theta)+b(16(1+\theta)+}<0 . \\
& \left.b\left(-8+2 \theta(1+4 \theta-2 b(1+\theta))-K(1+\theta)\left(8-b^{2}(1+\theta)\right)\right)\right)
\end{aligned}
$$


When $m=2 / 4$ and $\frac{3}{44}(35-3 \sqrt{97})<\theta<1$, compare price changes before and after technology sharing:

$$
\begin{aligned}
p_{1}^{I}-p_{1}^{S}= & \frac{a\left(K(2-b-b m)\left(4-b^{2}\right)-4\right)}{\left(4-b^{2}\right)^{2} K-8} \\
& a(-4+8 K-16 \theta-4 b(-2+K(1+m)-\theta(3+2 m))+ \\
-\frac{\left.b^{3}(1+\theta)(K(1+m)-\theta(3+2 m))+b^{2}\left(-4+\theta+4 \theta^{2}-2 K(1+\theta)\right)\right)}{8(-1+2 K-4 \theta)+b(16(1+\theta)+}<0 . & \left.b\left(-8+2 \theta(1+4 \theta-2 b(1+\theta))-K(1+\theta)\left(8-b^{2}(1+\theta)\right)\right)\right)
\end{aligned}
$$

When $m=3 / 4$ and $\frac{3}{44}(35-3 \sqrt{97})<\theta<1$, compare price changes before and after technology sharing:

$$
\begin{aligned}
p_{1}^{I}-p_{1}^{S}= & \frac{a\left(K(2-b-b m)\left(4-b^{2}\right)-4\right)}{\left(4-b^{2}\right)^{2} K-8} \\
& \frac{a(-4+8 K-16 \theta-4 b(-2+K(1+m)-\theta(3+2 m))+}{8(-1+2 K-4 \theta)+b(16(1+\theta)+} \\
\left.b\left(-8+2 \theta(1+4 \theta-2 b(1+\theta))-K(1+\theta)\left(8-b^{2}(1+\theta)\right)\right)\right) & \left.b^{3}(1+\theta)(K(1+m)-\theta(3+2 m))+b^{2}\left(-4+\theta+4 \theta^{2}-2 K(1+\theta)\right)\right)
\end{aligned} .
$$

The solution set about efficiency can be obtained as:

$$
\begin{gathered}
\frac{2(9-2 \theta) \theta}{(3-\theta)^{2}}<K<\frac{1}{3}\left(-7+\frac{45}{3-\theta}-\frac{20}{\theta}+\frac{\sqrt{3600-\theta(5280-\theta(3256-\theta(824-289 \theta)))}}{(3-\theta) \theta}\right) \\
p_{1}^{I}-p_{1}^{S}=\frac{a\left(K(2-b-b m)\left(4-b^{2}\right)-4\right)}{\left(4-b^{2}\right)^{2} K-8} \\
-\frac{\left.b^{3}(1+\theta)(K(1+m)-\theta(3+2 m))+b^{2}\left(-4+\theta+4 \theta^{2}-2 K(1+\theta)\right)\right)}{8(-1+2 K-4 \theta)+b(16(1+\theta)+}>0 . \quad \text { (C.14) } \\
\left.\quad b\left(-8+2 \theta(1+4 \theta-2 b(1+\theta))-K(1+\theta)\left(8-b^{2}(1+\theta)\right)\right)\right) \\
\left.K>\frac{1}{3}\left(-7+\frac{45}{3-\theta}-\frac{20}{\theta}+\frac{\sqrt{3600-\theta(5280-\theta(3256-\theta(824-289 \theta)))}}{(3-\theta) \theta}\right) . \quad \text { (C. } 15\right) .
\end{gathered}
$$

The certification of Port 2 is the same as the certification of Port 1, which is limited in length and will be omitted. Q.E.D.

Proof of Proposition 6 Proposition 6 reflects the changes in the shipping market demand due to the impact of blockchain technology sharing behavior in the shipping market. The discussion ideas are the same as Proposition 5. The following uses Port 1 as an example to illustrate the certification process. By querying the calculation results, the demand for the Port 1 investment scenario and the sharing scenario are respectively: $q_{1}^{I}=\frac{a\left(K(2-b-b m)\left(4-b^{2}\right)-4\right)}{\left(4-b^{2}\right)^{2} K-8}$ and 
$q_{1}^{S}=\frac{a\left(K(2-b-b m)\left(4-b^{2}(1+\theta)\right)-(4-b(4+b) \theta)(1-2(1+m) \theta)\right)}{-8+2 b(8+b) \theta-4 b(-4+b(2+b)) \theta^{2}-4\left(8+b^{3}\right) \theta^{3}+8 b^{2} \theta^{4}+K\left(-4+b^{2}(1+\theta)\right)^{2}}$. Therefore, we can get changes in demand before and after sharing. First, the value range of investment efficiency needs to be considered. From the original calculation, the efficiency constraints of investment scenarios and sharing scenarios can be obtained: $K>\frac{8}{16-8 b^{2}+b^{4}}$ and $K>\frac{8+32 \theta+2 b(-8(1+\theta)+b(4-\theta(1+4 \theta-2 b(1+\theta))))}{\left(4-b^{2}(1+\theta)\right)^{2}}$. Because of the competition intensity parameter $b=1$, so we can get $K>\frac{8}{9}$ and $K>$ $\frac{8+32 \theta+2(4-8(1+\theta)-\theta(1+4 \theta-2(1+\theta)))}{(3-\theta)^{2}}$. When $\frac{8}{9}-\frac{8+32 \theta+2(4-8(1+\theta)-\theta(1+4 \theta-2(1+\theta)))}{(3-\theta)^{2}}>0,0<\theta<$ $\frac{3}{44}(35-3 \sqrt{97})$; When $\frac{8}{9}-\frac{8+32 \theta+2(4-8(1+\theta)-\theta(1+4 \theta-2(1+\theta)))}{(3-\theta)^{2}}<0, \frac{3}{44}(35-3 \sqrt{97})<\theta<1$. Therefore, we can determine the value of the profit-sharing ratio $\theta$ under different restrictions.

When $m=1 / 4$ and $0<\theta<\frac{3}{44}(35-3 \sqrt{97})$, compare the demand changes before and after technology sharing:

$$
\begin{gathered}
q_{1}^{I}-q_{1}^{S}=\frac{a\left(K(2-b-b m)\left(4-b^{2}\right)-4\right)}{\left(4-b^{2}\right)^{2} K-8} \\
-\frac{a\left(K(2-b-b m)\left(4-b^{2}(1+\theta)\right)-(4-b(4+b) \theta)(1-2(1+m) \theta)\right)}{-8+2 b(8+b) \theta-4 b(-4+b(2+b)) \theta^{2}-}<0 . \\
4\left(8+b^{3}\right) \theta^{3}+8 b^{2} \theta^{4}+K\left(-4+b^{2}(1+\theta)\right)^{2}
\end{gathered}
$$

When $m=2 / 4$ and $0<\theta<\frac{3}{44}(35-3 \sqrt{97})$, compare the demand changes before and after technology sharing:

$$
\begin{aligned}
& q_{1}^{I}-q_{1}^{S}= \frac{a\left(K(2-b-b m)\left(4-b^{2}\right)-4\right)}{\left(4-b^{2}\right)^{2} K-8} \\
&-\frac{a\left(K(2-b-b m)\left(4-b^{2}(1+\theta)\right)-(4-b(4+b) \theta)(1-2(1+m) \theta)\right)}{-8+2 b(8+b) \theta-4 b(-4+b(2+b)) \theta^{2}-} \\
& 4\left(8+b^{3}\right) \theta^{3}+8 b^{2} \theta^{4}+K\left(-4+b^{2}(1+\theta)\right)^{2}
\end{aligned}
$$

When $m=3 / 4$ and $0<\theta<\frac{3}{44}(35-3 \sqrt{97})$, compare the demand changes before and after technology sharing:

$$
\begin{aligned}
q_{1}^{I}-q_{1}^{S}= & \frac{a\left(K(2-b-b m)\left(4-b^{2}\right)-4\right)}{\left(4-b^{2}\right)^{2} K-8} \\
& -\frac{a\left(K(2-b-b m)\left(4-b^{2}(1+\theta)\right)-(4-b(4+b) \theta)(1-2(1+m) \theta)\right)}{-8+2 b(8+b) \theta-}<0 . \\
& 4 b(-4+b(2+b)) \theta^{2}-4\left(8+b^{3}\right) \theta^{3}+8 b^{2} \theta^{4}+K\left(-4+b^{2}(1+\theta)\right)^{2}
\end{aligned}
$$

All in all, we can get $\theta \in\left(0, \frac{105-9 \sqrt{97}}{44}\right)$ and $K>\frac{8}{9}, q_{1}^{I}<q_{1}^{S}$.

Finally, when $m=1 / 4$ and $\frac{3}{44}(35-3 \sqrt{97})<\theta<1$, compare the demand changes before and after technology sharing:

$$
\begin{aligned}
& q_{1}^{I}-q_{1}^{S}=\frac{a\left(K(2-b-b m)\left(4-b^{2}\right)-4\right)}{\left(4-b^{2}\right)^{2} K-8} \\
& -\frac{a\left(K(2-b-b m)\left(4-b^{2}(1+\theta)\right)-(4-b(4+b) \theta)(1-2(1+m) \theta)\right)}{-8+2 b(8+b) \theta-4 b(-4+b(2+b)) \theta^{2}-4\left(8+b^{3}\right) \theta^{3}+8 b^{2} \theta^{4}+K\left(-4+b^{2}(1+\theta)\right)^{2}}<0 .
\end{aligned}
$$


When $m=2 / 4$ and $\frac{3}{44}(35-3 \sqrt{97})<\theta<1$, compare the demand changes before and after technology sharing:

$$
\begin{gathered}
q_{1}^{I}-q_{1}^{S}=\frac{a\left(K(2-b-b m)\left(4-b^{2}\right)-4\right)}{\left(4-b^{2}\right)^{2} K-8} \\
-\frac{a\left(K(2-b-b m)\left(4-b^{2}(1+\theta)\right)-(4-b(4+b) \theta)(1-2(1+m) \theta)\right)}{-8+2 b(8+b) \theta-4 b(-4+b(2+b)) \theta^{2}-}<0 . \\
4\left(8+b^{3}\right) \theta^{3}+8 b^{2} \theta^{4}+K\left(-4+b^{2}(1+\theta)\right)^{2}
\end{gathered}
$$

When $m=3 / 4$ and $\frac{3}{44}(35-3 \sqrt{97})<\theta<1$, compare the demand changes before and after technology sharing:

$$
\begin{aligned}
q_{1}^{I}-q_{1}^{S}= & \frac{a\left(K(2-b-b m)\left(4-b^{2}\right)-4\right)}{\left(4-b^{2}\right)^{2} K-8} \\
& -\frac{a\left(K(2-b-b m)\left(4-b^{2}(1+\theta)\right)-(4-b(4+b) \theta)(1-2(1+m) \theta)\right)}{-8+2 b(8+b) \theta-4 b(-4+b(2+b)) \theta^{2}-}>0 . \\
4\left(8+b^{3}\right) \theta^{3}+8 b^{2} \theta^{4}+K\left(-4+b^{2}(1+\theta)\right)^{2} &
\end{aligned}
$$

When $\theta \in\left(\frac{105-9 \sqrt{97}}{44}, 1\right)$ and $\frac{2(9-2 \theta) \theta}{(3-\theta)^{2}}<K<\frac{2}{3}\left(1+\frac{18}{3-\theta}-\frac{10}{\theta}+\sqrt{\frac{20(5-7 \theta)}{\theta^{2}}+\frac{549-\theta(222-49 \theta)}{(3-\theta)^{2}}}\right)$, $q_{1}^{I}>q_{1}^{S} ; \theta \in\left(\frac{105-9 \sqrt{97}}{44}, 1\right)$ and $K>\frac{2}{3}\left(1+\frac{18}{3-\theta}-\frac{10}{\theta}+\sqrt{\frac{20(5-7 \theta)}{\theta^{2}}+\frac{549-\theta(222-49 \theta)}{(3-\theta)^{2}}}\right), q_{1}^{I}<q_{1}^{S}$.

The certification of Port 2 is the same as the certification of Port 1, which is limited in length and will be omitted.

Proof of Proposition 7 Proposition 7 reflects the change in revenue of Ports 1 and 2 before and after sharing. This part takes Port 1 revenue as an example to illustrate the proof process. By searching the original results of the calculation, we can get the profit expression of Port 1 before and after sharing: $\pi_{1}^{I}=\frac{a^{2}\left(4-K(2-b-b m)\left(4-b^{2}\right)\right)^{2}}{\left(\left(4-b^{2}\right)^{2} K-8\right)^{2}}$ and

$\pi_{1}^{S}=\frac{a^{2}(1-\theta)(4+8 K+8 m+b(-4 K(1+m)+b K(-2+b+b m)(1+\theta)-(1+2 m)(4+b \theta)))^{2}}{\left(8(-1+2 K-4 \theta)+b\left(16(1+\theta)+b\left(-8+2 \theta(1+4 \theta-2 b(1+\theta))+K(1+\theta)\left(-8+b^{2}(1+\theta)\right)\right)\right)\right)^{2}}$.

We can get the change of grant before and after sharing. First of all, we need to consider the value range of investment efficiency. From the original calculation, we can get the restriction conditions of investment scenario and sharing scenario on efficiency respectively: $K>\frac{8}{16-8 b^{2}+b^{4}}$ and $K>\frac{8+32 \theta+2 b(-8(1+\theta)+b(4-\theta(1+4 \theta-2 b(1+\theta))))}{\left(4-b^{2}(1+\theta)\right)^{2}}$. Because of the competition intensity parameter $b=1$, so we can get $K>\frac{8}{9}$ and $K>\frac{8+32 \theta+2(4-8(1+\theta)-\theta(1+4 \theta-2(1+\theta)))}{(3-\theta)^{2}}$. When $\frac{8}{9}-\frac{8+32 \theta+2(4-8(1+\theta)-\theta(1+4 \theta-2(1+\theta)))}{(3-\theta)^{2}}>0,0<\theta<\frac{3}{44}(35-3 \sqrt{97})$; When

$$
\frac{8}{9}-\frac{8+32 \theta+2(4-8(1+\theta)-\theta(1+4 \theta-2(1+\theta)))}{(3-\theta)^{2}}<0, \quad \frac{3}{44}(35-3 \sqrt{97})<\theta<1 .
$$

Therefore, we can determine the value of the profit-sharing ratio $\theta$ under different restrictions.

When $m=1 / 4$ and $0<\theta<\frac{3}{44}(35-3 \sqrt{97})$, Compare the revenue changes before and after technology sharing:

$$
\pi_{1}^{I}-\pi_{1}^{S}=\frac{a^{2}\left(4-K(2-b-b m)\left(4-b^{2}\right)\right)^{2}}{\left(\left(4-b^{2}\right)^{2} K-8\right)^{2}}
$$




$$
\begin{gathered}
a^{2}(1-\theta)(4+8 K+8 m+b(-4 K(1+m)+ \\
-\frac{b K(-2+b+b m)(1+\theta)-(1+2 m)(4+b \theta)))^{2}}{(8(-1+2 K-4 \theta)+b(16(1+\theta)+} \\
\left.\left.b\left(-8+2 \theta(1+4 \theta-2 b(1+\theta))+K(1+\theta)\left(-8+b^{2}(1+\theta)\right)\right)\right)\right)^{2}
\end{gathered}
$$

When $\pi_{1}^{I}-\pi_{1}^{S}>0,0<\theta<\frac{105-9 \sqrt{97}}{44}$ and $\frac{8}{9}<K<K_{1}(\theta)$, or, $0<\theta<\frac{105-9 \sqrt{97}}{44}$ and $K>K_{2}(\theta)$;

When $\pi_{1}^{I}-\pi_{1}^{S}<0,0<\theta<\frac{105-9 \sqrt{97}}{44}$ and $K_{1}(\theta)<K<K_{2}(\theta)$;

When $m=1 / 4$ and $\frac{3}{44}(35-3 \sqrt{97})<\theta<1$, compare the revenue changes before and after technology sharing:

$$
\begin{aligned}
& \pi_{1}^{I}-\pi_{1}^{S}= \frac{a^{2}\left(4-K(2-b-b m)\left(4-b^{2}\right)\right)^{2}}{\left(\left(4-b^{2}\right)^{2} K-8\right)^{2}} \\
& a^{2}(1-\theta)(4+8 K+8 m+b(-4 K(1+m)+ \\
&-\frac{b K(-2+b+b m)(1+\theta)-(1+2 m)(4+b \theta)))^{2}}{(8(-1+2 K-4 \theta)+b(16(1+\theta)+} \\
&\left.\left.b\left(-8+2 \theta(1+4 \theta-2 b(1+\theta))+K(1+\theta)\left(-8+b^{2}(1+\theta)\right)\right)\right)\right)^{2}
\end{aligned}
$$

When $\pi_{1}^{I}-\pi_{1}^{S}>0, \frac{3}{44}(35-3 \sqrt{97})<\theta<\theta_{3}$ and $K_{1}(\theta)<K<K_{2}(\theta)$, or, $\frac{3}{44}(35-3 \sqrt{97})<$ $\theta<\theta_{3}$ and $K>K_{2}(\theta) ; \theta_{3}<\theta<\theta_{4}$ and $K_{1}(\theta)<K<K_{2}(\theta) ; \theta_{4}<\theta<1$ and $K>K_{2}(\theta)$.

When $\pi_{1}^{I}-\pi_{1}^{S}<0, \frac{3}{44}(35-3 \sqrt{97})<\theta<\theta_{3}$ and $\frac{18 \theta-4 \theta^{2}}{9-6 \theta+\theta^{2}}<K<K_{2}(\theta) ; \frac{18 \theta-4 \theta^{2}}{9-6 \theta+\theta^{2}}<$ $K<K_{2}(\theta)$ and $K>K_{2}(\theta) ; \theta_{3}<\theta<\theta_{4}$ and $\frac{18 \theta-4 \theta^{2}}{9-6 \theta+\theta^{2}}<K<K_{2}(\theta) ; \theta_{4}<\theta<1$ and $\frac{18 \theta-4 \theta^{2}}{9-6 \theta+\theta^{2}}<K<K_{4}(\theta)$.

In the same way, we can get $m=2 / 4$ and $m=3 / 4$, and the change of the Port 2 income. Due to space limitations, this part is omitted. Finally, according to the change of the relevant interval, the image expression of the optimal strategy of Port 1 and Port 2 can be obtained. Finally, a graphical representation of the balanced strategy of Port 1 and Port 2 is obtained. 